\title{
WestVirginiaUniversity
}

THE RESEARCH REPOSITORY @ WVU

Graduate Theses, Dissertations, and Problem Reports

2005

\section{Modeling and control of a small glass furnace}

Andrea R. Holladay

West Virginia University

Follow this and additional works at: https://researchrepository.wvu.edu/etd

\section{Recommended Citation}

Holladay, Andrea R., "Modeling and control of a small glass furnace" (2005). Graduate Theses, Dissertations, and Problem Reports. 1668.

https://researchrepository.wvu.edu/etd/1668

This Thesis is protected by copyright and/or related rights. It has been brought to you by the The Research Repository @ WVU with permission from the rights-holder(s). You are free to use this Thesis in any way that is permitted by the copyright and related rights legislation that applies to your use. For other uses you must obtain permission from the rights-holder(s) directly, unless additional rights are indicated by a Creative Commons license in the record and/ or on the work itself. This Thesis has been accepted for inclusion in WVU Graduate Theses, Dissertations, and Problem Reports collection by an authorized administrator of The Research Repository @ WVU. For more information, please contact researchrepository@mail.wvu.edu. 


\title{
MODELING AND CONTROL OF A SMALL GLASS FURNACE
}

\author{
Andrea R. Holladay \\ Thesis submitted to the \\ College of Engineering and Mineral Resources \\ at West Virginia University \\ in Partial Fulfillment of the Requirements for the Degree of
}

\author{
Master of Science \\ in \\ Mechanical Engineering \\ Larry E. Banta, Ph.D., Chair \\ Giampiero Campa, Ph.D. \\ Kenneth H. Means, Ph.D
}

Department of Mechanical Engineering

Morgantown, WV

2005

Keywords: Glass Furnace, Modeling, Control, Observer Design 


\title{
ABSTRACT \\ MODELING AND CONTROL OF A SMALL GLASS FURNACE
}

\begin{abstract}
Andrea Holladay
Most control systems currently used for glass furnaces monitor temperature with a thermocouple placed in the crown of the furnace and adjust the flow rate of the fuel to maintain a set point. The temperature measured is much closer to that of the combustion gasses within the furnace rather than the temperature of the glass. Models that predict the temperature of the glass are available in the form of complicated Computational Fluid Dynamics packages that are cost prohibitive to companies with small profit margins.

In this work, a simplified mathematical model has been developed to represent the dynamic performance of a small glass furnace. The output temperatures of the model are used to simulate the measurable and immeasurable parameters of a furnace.

Two system observers were designed. The first was a reduced order observer using only the currently measured combustion gas temperature for error feedback calculations. The second observer was designed using the measured combustion gas temperature and additional suggested refractory temperature measurements for feedback. It is shown that the observer based on combustion gas temperature does not accurately track the system states within a reasonable time period and is completely unable to track the system states when noise and disturbance inputs are introduced. It is then shown that the observer based on current and suggested temperature measurements has a fast response time and is robust to noise and disturbance.
\end{abstract}

Committee Members: Dr. Larry E. Banta (chair), Dr. Giampiero Campa, Dr. Kenneth H. Means 


\section{TABLE OF CONTENTS}

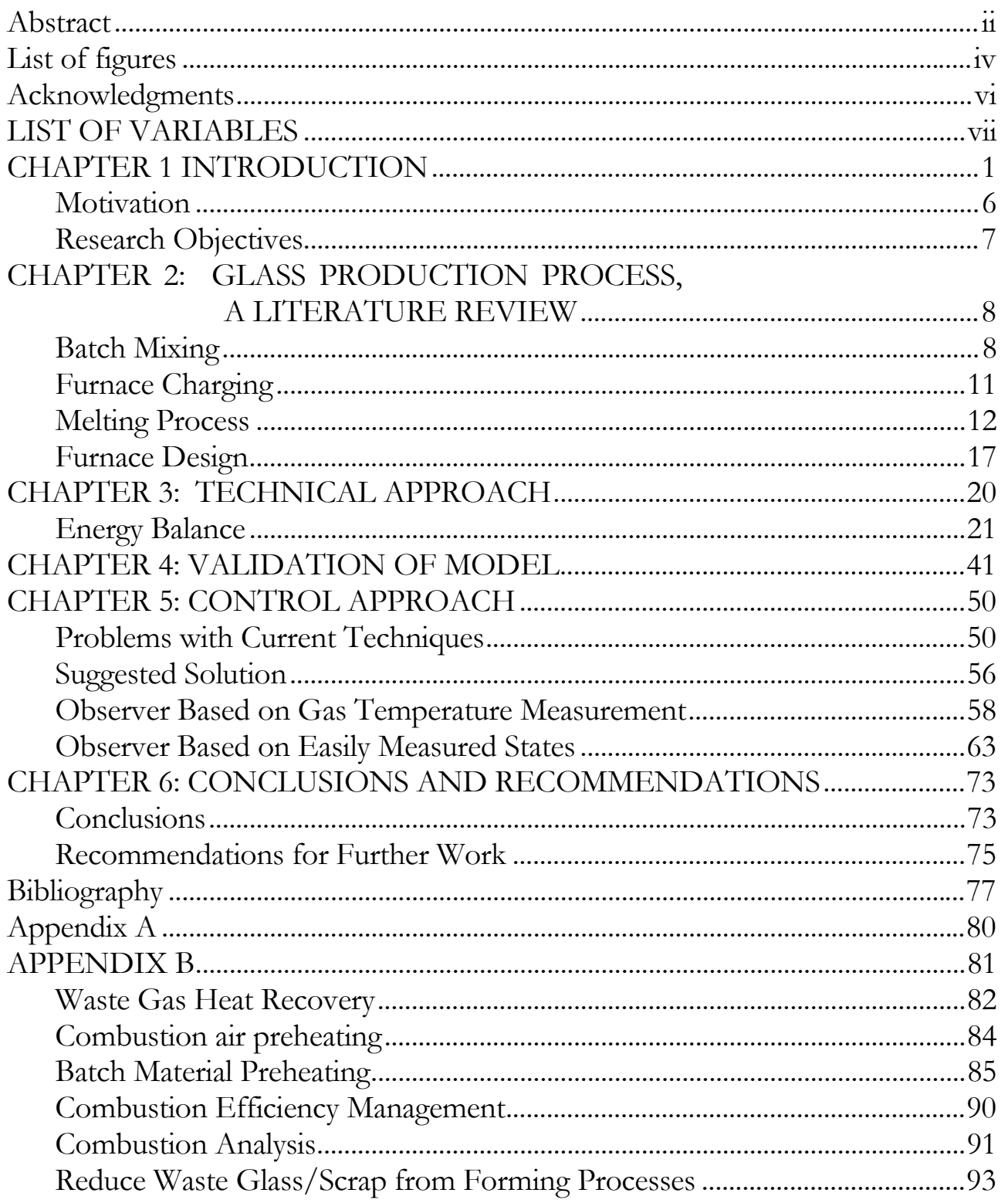




\section{LIST OF FIGURES}

Number

Page

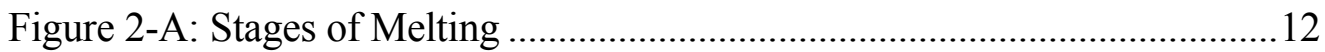

Figure 2-B: Ceramic Pot Used in Pot Furnace ..................................................... 17

Figure 2-C: Tank Furnace …………………………………..........................18

Figure 3-A: Heat Balance Diagram ................................................................22

Figure 3-B: Comparison of Linear and Nonlinear Radiation

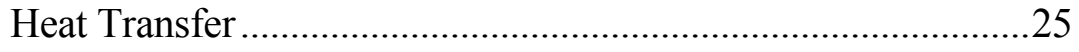

Figure 3-C: Pole-Zero Map of Open Loop Poles.................................................39

Figure 3-D: Pole Zero Map of Open Loop Poles Close to

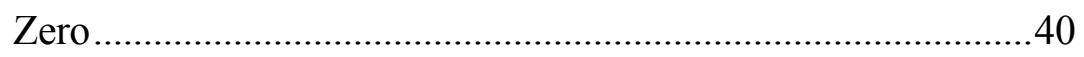

Figure 4-A: Simulink Model....................................................................

Figure 4-B: Available Energy to Furnace ………………………………….....4

Figure 4-C: Temperature of Glass Over Time - Cold Start..................................46

Figure 4-D: Temperature of Glass Over Time - Hot Start ..................................46

Figure 4-E: Response of Refractory Temperature for Cold

Furnace

Figure 4-F: Glass Temperature as a Function of Time - Hot

Start.

Figure 5-A: Calculated Output Temperatures ..................................................51

Figure 5-B: Fuel Flow Rate ..............................................................................51

Figure 5-C: Response Time with Ts Used as Feedback .....................................52

Figure 5-D: Increased Set Point For Ts ............................................................53

Figure 5-E: Effect of Glass Removal on $\mathrm{T}_{\mathrm{G}}, \mathrm{T}_{\mathrm{S}}$ Feedback ................................55

Figure 5-F: Simulink Block Diagram of Observer …………………………......58 


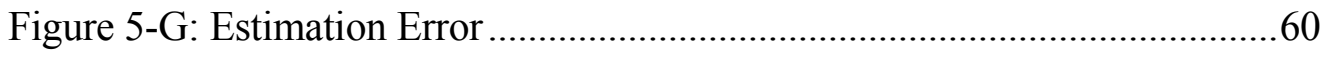

Figure 5-H: Estimated and Actual Glass Temperatures..................................61

Figure 5-I: Estimation Error with Noise .....................................................62

Figure 5-J: Simulink Model of Three State Observer .....................................65

Figure 5-K: Estimated and Actual Glass Temperatures Three State Feedback .........................................................................66

Figure 5-L: Estimation Error for Three State Feedback .................................67

Figure 5-M: Effect of Glass Removal on $\mathrm{T}_{\mathrm{G}}-$ Three State

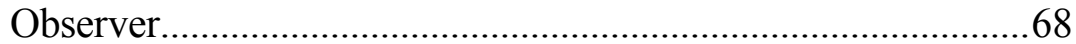

Figure 5-N: Detailed View of Glass Temperature with

Disturbance

Figure 5-O: Detailed View of Fuel Flowrate with

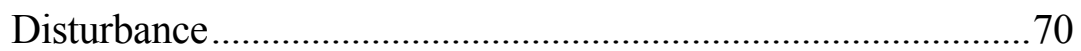

Figure 5-P: Flow rate of Fuel over Entire Simulation......................................70

Figure 5-Q: Estimation Error Over 24 Hour Period with

Noise.

Figure 5-R: Detailed View of Estimation Error..... 


\section{ACKNOWLEDGMENTS}

I would like to thank my friends and family for their patience and support during the writing of this thesis. Eric, Jennifer and Jason - thank you for never doubting that I would succeed. Mom and Dad, thank you for

your support and encouragement. A very special thank you to Matthew, Nicole, and Kristen for never complaining about the time I spent away from home and remembering that I love you and I am always thinking about you..

To my committee members, Dr. Kenneth Means and Dr. Giampiero Campa, thank you for your valuable feedback and your time spent in reading my thesis and answering questions.

Finally, I want to express my gratitude to my committee chairman, advisor, and friend, Dr. Larry Banta. Dr. Banta, without your encouragement during both my undergraduate and graduate careers, I would not be the engineer I am today. With your inspiration, I am able to step into the world unafraid to stand on my soapbox. 


\section{LIST OF VARIABLES}

\begin{tabular}{|c|c|}
\hline A & Area \\
\hline$\underline{\mathrm{A}}$ & State matrix \\
\hline $\mathrm{A} / \mathrm{F}$ & Air fuel ratio \\
\hline$\underline{\mathrm{B}}$ & Control matrix \\
\hline$\overline{\mathrm{C}}$ & Capacitance \\
\hline$\underline{\mathrm{C}}$ & Output matrix \\
\hline$\overline{c_{p}}$ & Specific heat \\
\hline$\underline{\mathrm{D}}$ & Noise matrix. \\
\hline $\bar{e}$ & Error vector \\
\hline g & Acceleration of gravity \\
\hline $\mathrm{h}$ & Heat transfer coefficient \\
\hline $\mathrm{H}$ & Height \\
\hline $\mathrm{L}$ & Length \\
\hline$\underline{\mathrm{L}}$ & Observer gain \\
\hline LHV & Lower heating value \\
\hline $\mathrm{m}$ & Mass \\
\hline MW & Molecular weight \\
\hline $\mathrm{P}$ & Pressure \\
\hline$\underline{\mathrm{P}}$ & Controllability matrix \\
\hline $\mathrm{Q}$ & Heat transfer \\
\hline$\underline{Q}$ & Observability Matrix \\
\hline $\mathrm{R}$ & Resistance \\
\hline$\underline{\mathrm{R}}$ & Gas constant \\
\hline $\mathrm{r}$ & Radius \\
\hline$\underline{\mathrm{R}}_{U}$ & Universal gas constant \\
\hline$\overline{\mathrm{T}}$ & Temperature \\
\hline $\mathrm{V}$ & Volume \\
\hline$\vec{V}$ & Velocity \\
\hline $\mathrm{W}$ & Width \\
\hline$X$ & Glass Level \\
\hline $\mathrm{x}$ & State vector \\
\hline$\varepsilon$ & Emissivity \\
\hline$\eta$ & Efficiency \\
\hline$\eta_{\mathrm{v}}$ & Viscosity \\
\hline$\rho$ & Density \\
\hline$\sigma$ & Stephan-Boltzmann constant \\
\hline
\end{tabular}




\section{INTRODUCTION}

Revolutionary advancements in glass manufacturing technology have been limited due to the conservative nature of the industry. Many of the processes used currently are only slight variations of those pioneered over 100 years ago. Until recently, the glass industry has been able to offset increasing fuel costs and more stringent environmental regulations with small, incremental advancements in technology. These advancements include improved refractories, higher efficiency burners, oxygen enrichment of combustion air, and preheating of batch materials using waste heat from stack gasses.

Improved refractory bricks and high efficiency burners have been installed in existing furnaces as the life cycle of the previous bricks and burners has expired, but oxygen enrichment and waste gas preheating of batch materials are not common. Although these technologies are readily available, industry-wide implementation has been restricted by high capital investment and perceived long capital recovery periods.

The majority of the research and development over the past several decades has been focused on improving efficiency and emissions of large- 
scale furnaces rather than small or mid-sized furnaces. Some technologies developed for the float glass and fiberglass industries can be applied to smaller furnaces; however, detailed models of the heat transfer and melting/refining processes are either held proprietary or are beyond the economic and technical reach of most of the hand glass industry. Although each hand glass plant uses only a fraction of the energy consumed by a float glass or container plant, the smaller companies employ far more people per ton of product. The demise of these smaller companies is having a significant negative effect on local and state economies.

Recent energy price increases and the resulting increase in the cost of goods portion represented by energy are resulting in decreasing and sometimes negative profit margins. Innovative designs for medium and small scale glass furnaces could increase profitability throughout the industry. Design improvements which increase efficiency and production of smaller furnaces must be made for small companies to survive in the future.

The cyclic loading and melting of raw materials in smaller furnaces creates thermal stresses that can cause cracking and failure of the containers. Life cycles of these furnaces are often described in terms of melts instead of years. Conversations with local glass manufacturers indicate that typical life 
cycles of ceramic pots range from 300-800 melts depending on the type of glass being produced. This number of melts corresponds to a 1-4 year life cycle.

Some larger tank furnaces incorporate continuous melting, but do not have continuous batch feeding. Batch materials are added to these furnaces at set time intervals. Continuous feeding of batch materials combined with continuous heating processes would eliminate the thermal stresses caused by multiple reheating cycles and improve the overall efficiency of the furnace. High production furnaces are almost exclusively continuous operations. Continuous melting furnaces promote steady state operation and, in turn, controllability. Controllability allows for efficient and effective use of energy.

Strategies for improving productivity include:

- Increasing the amount of product per unit time

- Decreasing breakage and waste/scrap

- Decreasing energy per ton of product

- Decrease labor needed per ton of product

- Increase furnace lifespan

Many of these objectives can be addressed via two synergistic paths

1. Improve furnace structural design 
2. Improve control of combustion, batching and feeding Work in this thesis focuses on the second objective.

Most small companies rely on human observation and judgment to monitor and control operational aspects such as air/fuel ratio. Electronic monitoring systems in most small glass furnaces are currently very primitive, sometimes limited to a single thermocouple per tank located in the crown of the furnace.

Crown temperature measurements are unreliable indicators of glass temperature because of the large thermal capacitance of the glass melt and the wide variety of other factors affecting the heat transfer between the combustion gasses and the melt. These include glass color, depth and emissivity, along with flame temperature, chemical composition and furnace construction. In addition, viscosity is one of the most critical parameters in the forming process. A temperature change of 50-100 degrees produces and order of magnitude difference in viscosity; therefore, accurate knowledge of and control of glass temperature is crucial for maintaining product quality.

Some operations have systems that control air/fuel ratio, furnace pressure, and temperature, but these systems work independently. Systems that 
monitor and control multiple parameters in closed-loop form are limited. Existing control problems include:

- Air/Fuel ratio - $\mathrm{A} / \mathrm{F}$ ratio directly impacts combustion efficiency but must be balanced with the required furnace atmospheric conditions. Producing the desired color can depend on the presence of either an oxidizing or reducing furnace atmosphere.

- Firing rate - the large system time constant and variable heat transfer characteristics due to fuel chemistry, moisture content and air/fuel ratios require an adaptive-predictive control system

- Furnace pressure - Infiltration and exfiltration are usually only estimations based on furnace area but have a significant impact on thermal efficiency and furnace atmosphere

Since these complex control issues are all interconnected, separate PID controllers are not as effective as integrated control of all process variables. Alternative algorithms may be required for products that require unique 
conditions, but in all cases, adaptive control that can adjust and optimize for slight variations in normal operation, account for glass removal, and compensate for furnace aging will be a beneficial improvement to existing control systems.

\subsection{Motivation}

Motivation for this master's thesis has come from the recognition of an industry-wide need for energy conservation for both environmental conservation and corporate profitability. Due to the dramatic increase in the cost of energy threatening the viability of small glass industry, there is a substantial need for an affordable, energy efficient, small capacity glass furnace design. 


\subsection{Research Objectives}

The main objective of this research is to develop a cost effective method of controlling a small capacity glass furnace. Recommendations for improvements in energy efficiency and process instrumentation will also be included. The project can be divided into the following tasks:

- Mathematical model of glass production process

- Development of a new approach to small glass furnace control

- Survey of existing technologies for energy conservation 


\section{GLASS PRODUCTION PROCESS, A LITERATURE REVIEW}

The glass production process can be separated into four phases - batch mixing, furnace charging, melting, and forming.

\subsection{Batch Mixing}

Batch mixing, also called "batching," includes the creation of a mixture of raw materials designed to produce the desired end product. Raw materials used in batching can be divided into groups based on their function in the melting process. Shelby ${ }^{1}$ separates batch materials into five groups glassformers, fluxes, property modifiers, colorants, and fining agents. Although formulae for batch mixtures vary greatly among producers and are highly dependent on the intended use of the finished product, the majority of batch material used in a mixture is always a glassformer. Glassformers are the compounds that create the structural basis of the glass. The most common glassformers are silica, $\left(\mathrm{SiO}_{2}\right)$, boric oxide, $\left(\mathrm{B}_{2} \mathrm{O}_{3}\right)$, and phosphoric oxide, $\left(\mathrm{P}_{2} \mathrm{O}_{5}\right)$. Generic names of glasses are based on the type, or types, of glassformer used in the batch material. 
A flux is a compound that is added to the batch to lower the melting temperature of the glassformer. Pure silica has a melting temperature over $2100^{\circ} \mathrm{C}$. Adding a flux to the batch mixture can lower the melting temperature by over $500^{\circ} \mathrm{C} .{ }^{1}$ The most common fluxes are soda ash (sodium oxide $\left(\mathrm{Na}_{2} \mathrm{O}\right)$ mixed with sodium carbonate $\left.\left(\mathrm{Na}_{2} \mathrm{CO}_{3}\right)\right)$, limestone $\left(\mathrm{CaCO}_{3}\right)$, and potassium carbonate (potash, $\left.\mathrm{K}_{2} \mathrm{CO}_{3}\right)$. Lead oxide, $(\mathrm{PbO})$, the compound used to make crystal glass, is also an effective fluxing agent, but usage is decreasing due to environmental regulations concerning heavy metals.

Adding flux to the batch will decrease the melting temperature, but weaken the chemical structure of the glass. Adding property modifiers, such as alumina $\left(\mathrm{AlO}_{3}\right)$, will increase the durability of the chemical structure. Batch recipes are designed to balance the effects of the flux and the property modifier in a manner that suits the desired purpose of the finished product.

Colorants are chemical compounds added to the batch mixture to create a desired tint in the finished glass. Most colorants are transition metals including iron, manganese, cobalt, copper, chromium and tungsten. Transition metals have valence electrons (the electrons that combine with other elements) in more than one shell or level. Since each level of the transition metal absorbs 
light of a different frequency, the visible colors are a result of electron transmission between valence levels in the ion. Other colorants, including sulfur and selenium, replace some of the oxygen in the glass and form new compounds with different absorption characteristics than the batch compounds. $^{2}$

Fining agents are used to help remove bubbles from the molten glass. Bubbles can be caused by chemical reactions during the melting process, breakdown of the refractory lining of the furnace or by gasses trapped between batch particles. These bubbles must be removed to improve the quality of the glass. Compounds including arsenic and antimony oxides $\left(\mathrm{AS}_{2} \mathrm{O} 5, \mathrm{Sb}_{2} \mathrm{O}_{5}\right)$, potassium and sodium nitrates $\left(\mathrm{KNO}_{3}, \mathrm{NaNO}_{3}\right)$, salt, $(\mathrm{NaCl})$, sulfate $\left(\mathrm{SO}_{3}\right)$, and several fluorides $\left(\mathrm{CaF}_{2}, \mathrm{NaF}, \mathrm{NaAlF}_{6}\right)$ can be added separately or in combination for the fining portion of glass production. Small bubbles in the molten glass are carried to the surface with larger bubbles formed by chemical reactions induced by the addition of the fining agents. ${ }^{1}$ 


\subsection{Furnace Charging}

Furnace charging is the process by which the raw materials are fed into the furnace. Materials are added to the furnaces either continuously or in batches. Continuous batch feeding is accomplished with the use of either a screw, blanket or pusher type charger. All three types of chargers push the batch material into the furnace at a steady rate. A screw charger is a large helical auger that moves the batch toward the furnace as it rotates. Blanket chargers push horizontal lines of batch towards the furnace with a long bar. And pusher chargers feed small amounts of batch into the center of the melter by means of a rocking mechanism. ${ }^{2}$

Batch charging is used on small furnaces with capacities of less than 10 tons per day. Batch charging is a manual procedure; employees use shovels to load batch materials into a furnace. Some operations require small amounts of batch to be added to the furnace 2-3 times per hour, while other operations only load batch once per day. 


\subsection{Melting Process}

The melting process converts raw materials to molten glass. This process can be divided into 4 stages: melting, fining, homogenizing and heat conditioning. These stages are not completely sequential from the charging end of the furnace to the forming end. Instead, the stages overlap as the materials progress towards the outlet of the furnace. For a batch furnace the position of the stages along the length of the furnace can be equated to the time from loading the batch to the removal of glass. Figure 2-A shows the overlap of stages.

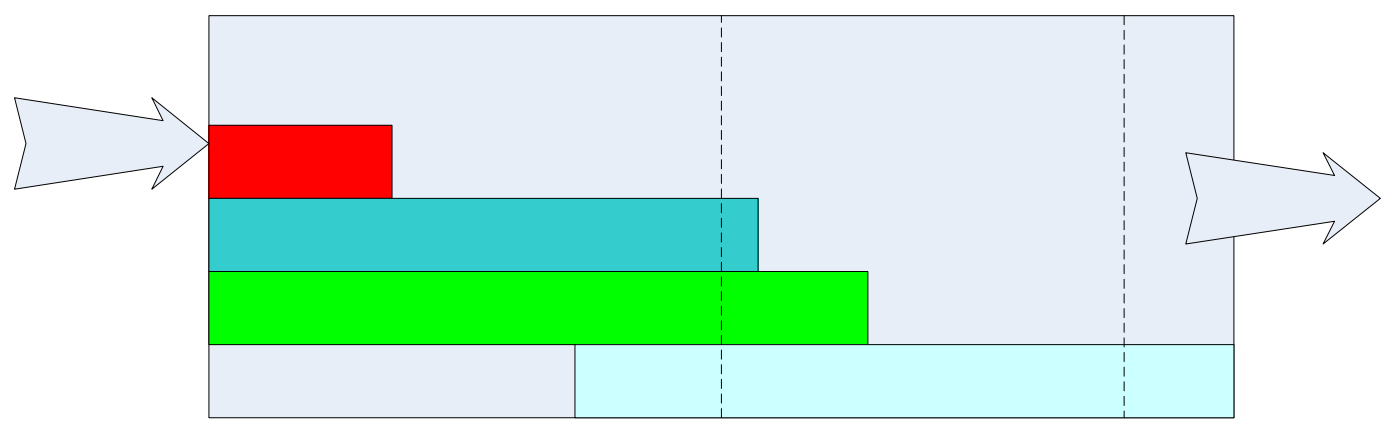

Figure 2-A: Stages of Melting $^{3}$ 


\subsubsection{Melting}

Melting begins upon introduction of the batch material to the charging end of the furnace. As heat is added to the furnace, water in the batch evaporates and chemical compounds break down and begin to transition to a liquid stage. The evaporation of water decreases the volume of the melt and increases the energy consumption of the furnace, but the presence of water cannot be eliminated. Many of the compounds in batch materials are hygroscopic and will absorb water from the atmosphere. Also, raw materials are often sprayed with water to decrease dust during mixing and transportation. As the chemical compounds break down, and become liquid, several gasses, including $\mathrm{CO}_{2}, \mathrm{SO}_{2}$, and $\mathrm{SO}_{3}$, are formed. The formation of these gasses produces bubbles which must be removed before the forming process.

\subsubsection{Fining}

The removal of bubbles in the melt occurs in the fining stage.

Bubble behavior in the melt can be described by Stokes' Law:

$$
\vec{V}_{s}=\frac{2 g\left(\rho_{s}-\rho_{l}\right) r^{2}}{9 \eta_{v}}
$$


where

- $\quad \vec{V}_{s}=$ Velocity of a solid sphere of a known density, $\rho_{\mathrm{s}}$

- $\mathrm{g}=$ acceleration of gravity

- $\left(\rho_{\mathrm{s}}-\rho_{1}\right)=$ difference in the density of the sphere and the surrounding fluid,

- $r=$ radius of the sphere

- $\quad \eta_{\mathrm{v}}=$ viscosity of the fluid

which states that the velocity of a solid sphere is proportional to the square of the radius of the sphere. A variation of Equation (1) is used by Shelby ${ }^{1}$ to describe the behavior of a gas filled bubble in a viscous liquid.

$$
\vec{V}_{b}=\frac{3}{2} \vec{V}_{s}
$$

where $\vec{V}_{b}$ is the velocity of the bubble.

Because bubble velocity is dependent upon size, larger bubbles will quickly rise to the top of the melt. Small bubbles move so slowly that time required to reach the surface can cause delays in production. The presence of 
fining agents in the batch material aids in the removal small bubbles by creating larger bubbles that will carry the small bubbles to the surface.

Creating an upward flow within the melt can help increase the rate of bubble rise. Mechanical stirring, or compressed air forced through nozzles located in the bottom of a tank, can be used to produce the necessary current. The creation of hotter and cooler sections of a furnace by localized heating can induce convective currents that promote fining and the geometric design of the bottom of the furnace can also produce the desired upward flow. ${ }^{1}$

\subsubsection{Homogenizing}

The homogenizing phase of melting begins with the initial melting and ends when the material in the furnace reaches the point at which the melt is free of batch material and of relatively uniform consistency. The degree of homogeneity required is based on the desired properties of the formed product. The homogenizing phase includes the entire melting and fining phases because the compounds in the melt are continually reacting to form the final product. Factors that effect the time required for a melt to homogenize include: particle size of the batch materials, combination of batch materials, temperature, and mixing patterns from either mechanical or convective currents. ${ }^{2}$ 


\subsubsection{Heat Conditioning}

The heat conditioning phase is the time period in which the melt is brought to the temperature required for the intended forming process. Heat conditioning creates a uniform temperature in the portion of glass at the forming end of the furnace. The time required for heat conditioning is dependent upon the volume of the glass in the forming end, the desired forming temperature, and the flow rate of glass to the forming process.

\subsubsection{Forming}

Forming is the process that is applied to the molten glass as it leaves the furnace. Forming includes molding, hand blowing, floating, and glass fiber production. Although the various forming methods are not the focus of this thesis, the quality issues affecting the usability of the glass for each method are directly related to the melting process. ${ }^{2}$ 


\subsection{Furnace Design}

Smaller furnaces, those with a production of less than 10 tons/day, are usually classified as one of two basic types - pot furnaces and tank furnaces. The fundamental difference in these two types is how the portion of the furnace that holds the glass is constructed. In pot furnaces, the container that holds the glass is constructed of ceramic clay and looks like a large, sometimes covered, crucible. The bottom and sides are usually formed in pieces and then pressed together to form the body of the pot; although, some monolithic designs exist, which are molded as a single unit. Figure 2-B is a picture of the type of ceramic pot used in a pot furnace.

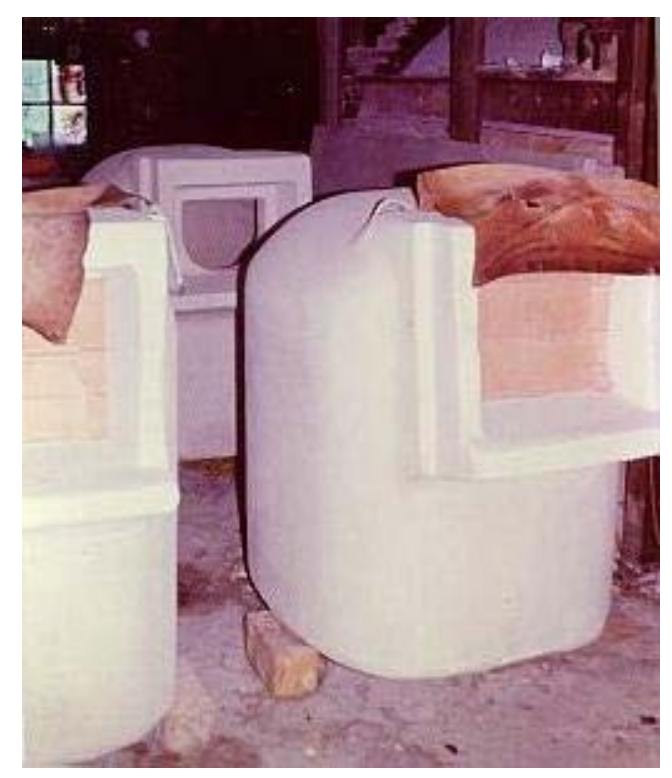

Figure 2-B: Ceramic Pot Used in Pot Furnace ${ }^{4}$ 
Tank furnaces are constructed of refractory similar in size to bricks used in the construction industry. The bricks are stacked together without mortar to form a tank to hold the molten glass. The bricks are stabilized by an exterior frame usually made of steel. Molten glass seeps through cracks between the refractory bricks until it reaches the point where it cools enough to solidify. A picture of a tank furnace is included as Figure 2-C.

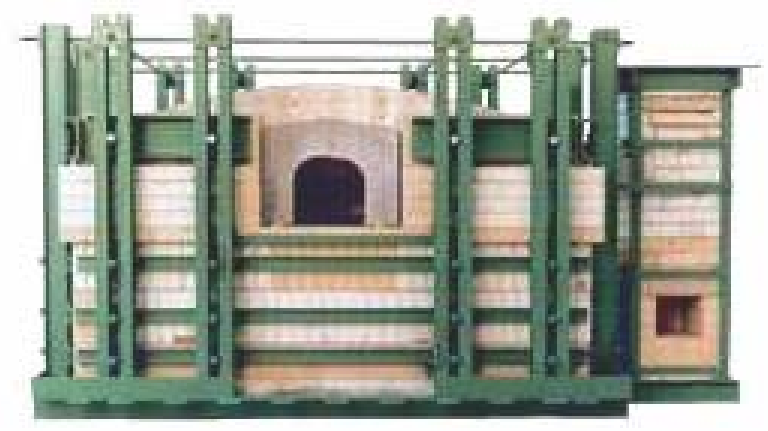

Figure 2-C: Tank Furnace ${ }^{5}$

Pot furnaces and smaller tank furnaces, called day tanks, are both used in the same manner. Raw materials are loaded into the pot or tank, the material is melted and held at a desired temperature, then the molten glass is taken out for production purposes. Most furnaces with a production rate of less than 5 tons per day are batch fed pot or day tanks. These furnaces are not recharged until the molten glass in the pot or tank has been depleted. The production of 
glass from pot and day tanks happens in cycles because of the time required to bring the large amount of raw materials to the desired temperature. Some batch fed tank furnaces that produce over 3 tons of glass per day operate with more frequent batch charging (2-3 times per hour). The molten glass in these furnaces is maintained at a relatively constant level and production for these furnaces is usually continuous. ${ }^{2}$ 


\section{TECHNICAL APPROACH}

Glass quality and workability is highly dependent upon temperature. Nearly all of the thermal and mechanical properties of glass vary greatly with temperature; therefore, it is desired to maintain a near constant glass temperature especially during homogenizing and working periods.

Current control systems monitor the temperature of combustion gasses near the top of the furnace by means of a shielded thermocouple placed in the crown. Temperature set points are maintained by changes in the flow rate of fuel to the burner. This type of system can be effective in controlling the temperature of the stack gasses to some degree, but not effective in controlling the glass temperature. Although the combustion gas temperature is related to the rate of heat transfer to the glass, changes in the combustion gas temperature are not directly related to changes in the temperature of the glass.

In small furnaces, the thermocouple is separated from the glass by the flame. Changes in the sensed temperature are delayed only by the time constant of the thermocouple and the propagation of the flame from the burner to the location of the thermocouple. This delay is very small when compared 
to the time constant of the entire system because it does not include the thermal capacitance of the glass or the refractory walls

\subsection{Energy Balance}

In order to predict the behavior of the glass temperature in relation to the measured crown temperatures, an energy balance was performed using thermodynamic and energy conservation laws. The model used for this work was a lumped-parameter, simplified model of the furnace and its contents. The glass was considered to be "well-stirred" and the refractory masses were considered to be of uniform temperature within the two defined zones. It is recognized that this is a gross simplification of the situation; however, it proved adequate for establishing energy flow relationships accurate enough to allow control of the system. This model structure allows us to account for thermal capacitances in the system while maintaining a reasonable computational burden on the control system computer.

A diagram of the heat balance is shown in Figure 3-A.. 


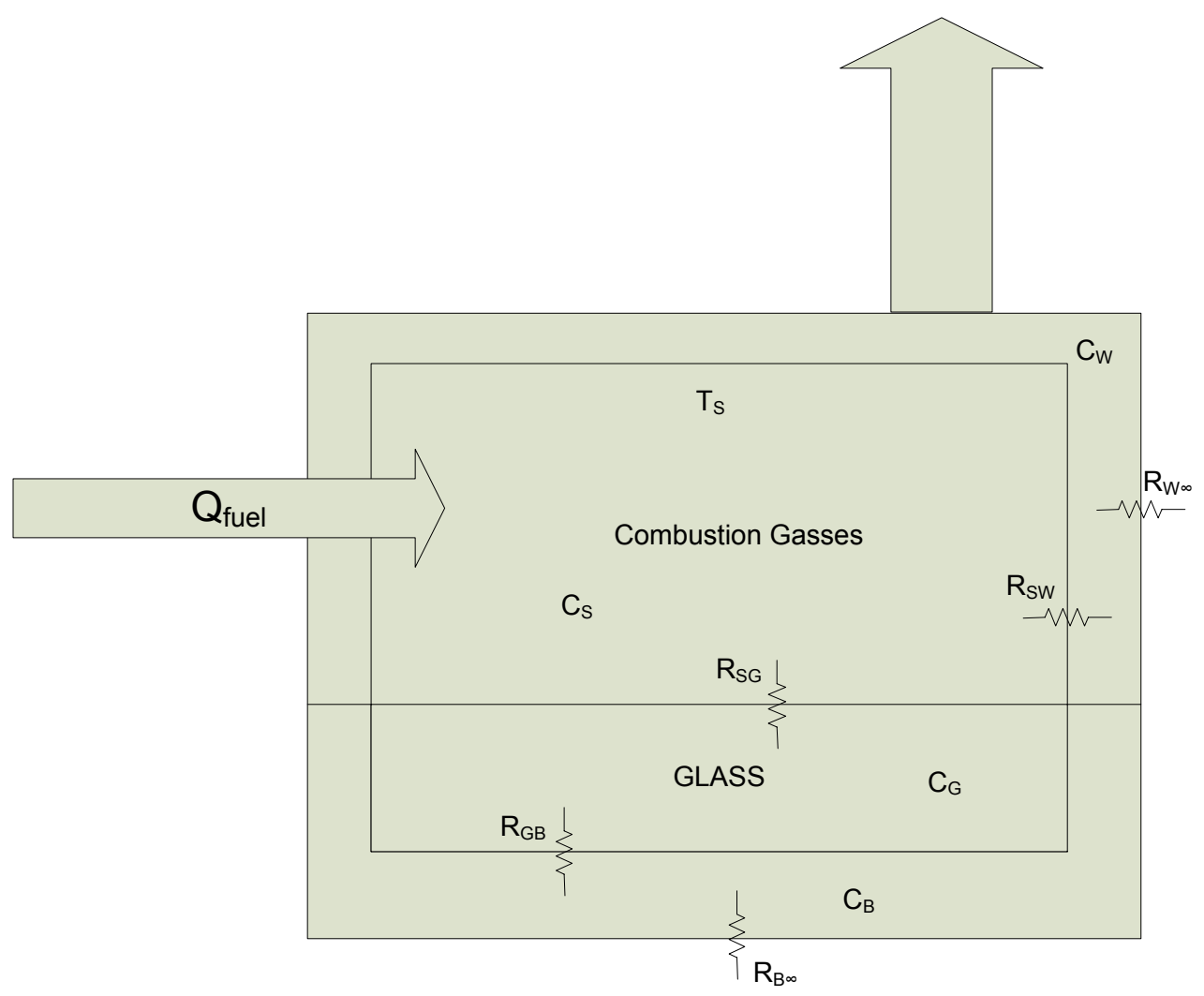

Figure 3-A: Heat Balance Diagram

The energy balance was separated into four parts corresponding to the components of the system that store energy. These parts and the related subscripts are as follows: the combustion gasses (subscript S), the glass (subscript G), the refractory structure at the bottom of the furnace that is in contact with the glass (subscript B) and the refractory structure above the surface of the glass (subscript W). 
For the combustion gas energy balance the energy sources are:

$$
\dot{Q}_{\text {fuel }}
$$

The energy sinks are:

$$
\begin{aligned}
& \dot{Q}_{S} \\
& \dot{Q}_{G} \\
& \dot{Q}_{W}
\end{aligned}
$$

Law of Conservation of Energy states that:

$$
\dot{Q}_{f u e l}=\dot{Q}_{G}+\dot{Q}_{W}+\dot{Q}_{S}
$$

Due to the high temperature environment and characteristics of the system, radiation is the dominant mode of heat transfer from the combustion gasses to the refractory wall and the glass. The convection coefficient has been shown to be more than two orders of magnitude smaller than the radiation coefficient. $^{6}$ 
Assuming that shape factors for radiation are near unity, the energy from radiative heat transfer has the form:

$$
\dot{Q}=\sigma \varepsilon A\left(T_{1}^{4}-T_{2}^{4}\right)
$$

The mean temperature of the combustion gasses and the glass temperature was used to linearize the heat transfer function and results in the following form:

$$
\dot{Q}=4 \sigma \varepsilon A \bar{T}^{3}\left(T_{1}-T_{2}\right)
$$

Figure 3-B shows that the linearization is valid at furnace operating conditions. 


\section{Comparison of Linear and Non-linear Radiation Heat Transfer}

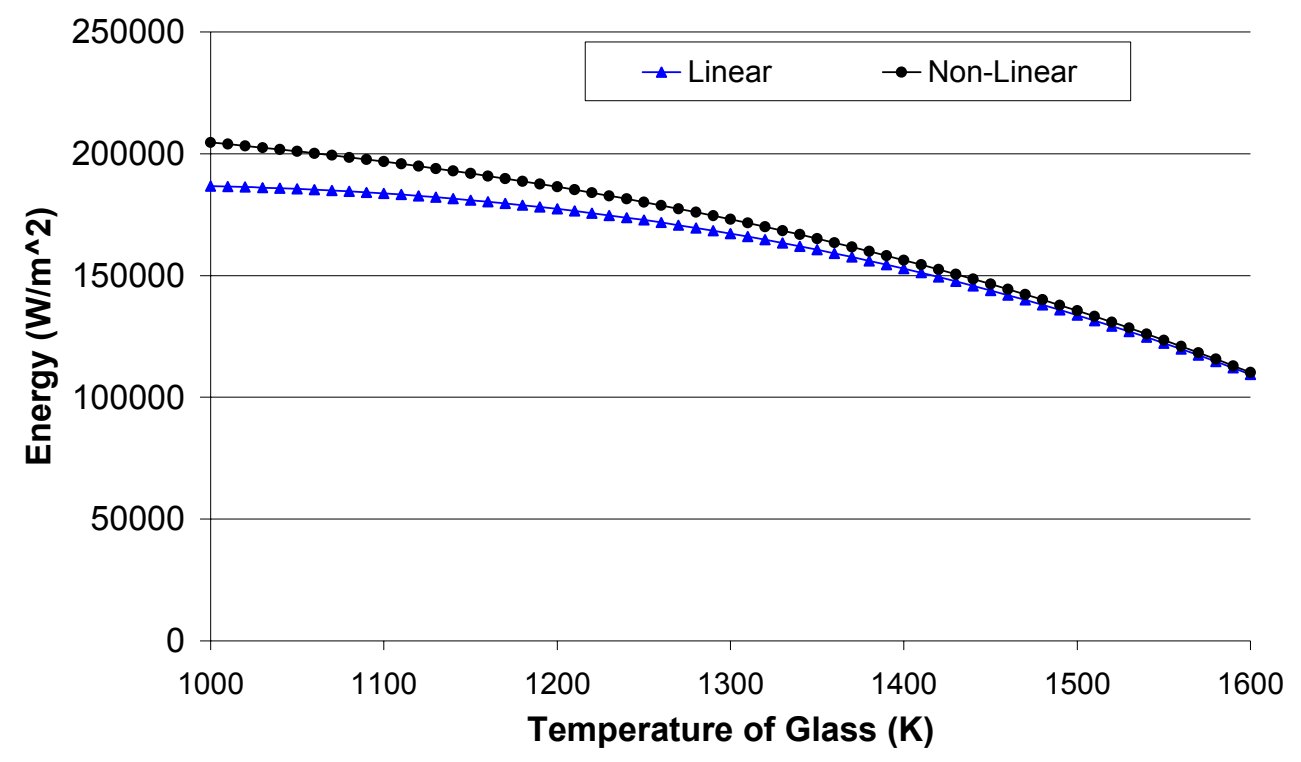

Figure 3-B: Comparison of Linear and Nonlinear Radiation Heat

\section{Transfer}

The linearized form is

$$
\dot{Q}=h A\left(T_{1}-T_{2}\right)
$$

Where $\mathrm{h}$ is a generalized heat transfer coefficient and $\mathrm{A}$ is the parameter area. The heat transfer coefficients for the combustion gasses to the glass and to the wall are respectively: 


$$
\begin{aligned}
& h_{S G}=4 \sigma \varepsilon \bar{T}_{S G}^{3} \frac{W}{m^{2} K} \\
& h_{S W}=4 \sigma \varepsilon \bar{T}_{S W}^{3} \frac{W}{m^{2} K}
\end{aligned}
$$

where:

- $\sigma=$ Stephan-Boltzmann constant $\left(5.67 \times 10^{-8} \frac{W}{K^{4} m^{2}}\right)$

- $\varepsilon=$ emissivity of combustion gasses

- $\quad \bar{T}_{S G}=\frac{T_{S}+T_{G}}{2}(\mathrm{~K})$

- $\bar{T}_{S W}=\frac{T s+T w}{2}(\mathrm{~K})$

- $\mathrm{T}_{\mathrm{S}}=$ Temperature of combustion gasses $(\mathrm{K})$ this is the temperature measured by the thermocouple and for the purposes of this model, assumed to be approximately the same as the temperature of the stack gasses

- $\quad \mathrm{T}_{\mathrm{W}}=$ Temperature of furnace wall $(\mathrm{K})$

- $\mathrm{T}_{\mathrm{G}}=$ Temperature of glass $(\mathrm{K})$ 
Rearranging and expanding gives:

$$
C_{s} \frac{d T_{s}}{d t}=\dot{Q}_{\text {fuel }}-\frac{A_{W}}{R_{S W}}\left(T_{S}-T_{W}\right)-\frac{A_{G}}{R_{S G}}\left(T_{S}-T_{G}\right)
$$

where

- $\mathrm{C}_{\mathrm{S}}=\dot{m} c_{p s}$ the capacitance of the combustion gasses

- $\frac{d T_{s}}{d t}$ is the time rate of change of the temperature of the combustion gasses

- $\mathrm{A}_{\mathrm{W}}$ is the area of the refractory surface above the glass level $\left(\mathrm{m}^{2}\right)$

- $\mathrm{A}_{\mathrm{G}}$ is the surface area of the glass $\left(\mathrm{m}^{2}\right)$

- $R_{S W}=\frac{1}{h_{S W}} \frac{m^{2} K}{W}$

- $R_{S G}=\frac{1}{h_{S G}} \frac{m^{2} K}{W}$

The energy balance equation for the glass after rearranging and expanding is:

$$
C_{G} \frac{d T_{G}}{d t}=\frac{A_{G}}{R_{S G}}\left(T_{S}-T_{G}\right)-\frac{A_{B}}{R_{G B}}\left(T_{G}-T_{B}\right)
$$


where:

- $\mathrm{C}_{\mathrm{G}}=\dot{m} c_{p G}$ the capacitance of the glass

- $\frac{d T_{G}}{d t}$ is the time rate of change of the temperature of the glass

- $\mathrm{A}_{\mathrm{B}}$ is the area of the refractory surface in contact with the glass $\left(\mathrm{m}^{2}\right)$

- $\mathrm{T}_{\mathrm{B}}$ is the temperature of the refractory in contact with the glass $(\mathrm{K})$

- $R_{S G}=\frac{1}{h_{S G}} \frac{m^{2} K}{W}$ with $\mathrm{h}_{\mathrm{SG}}$ the heat transfer coefficient between the combustion gasses and the glass

- $\quad R_{G B}=\frac{1}{h_{G B}} \frac{m^{2} K}{W}$ with $\mathrm{h}_{\mathrm{GB}}$ the heat transfer coefficient between the glass and the refractory

The energy balance equation for the refractory in contact with the glass is then:

$$
C_{B} \frac{d T_{B}}{d t}=\frac{A_{B}}{R_{G B}}\left(T_{G}-T_{B}\right)-\frac{A_{B}}{R_{B \infty}}\left(T_{B}-T_{\infty}\right)
$$


where:

- $\mathrm{C}_{\mathrm{B}}=\dot{m} c_{p B}$ the capacitance of the refractory

- $\frac{d T_{B}}{d t}$ is the time rate of change of the temperature of the refractory in contact with the glass

- $R_{B \infty}=\frac{1}{h_{B \infty}} \frac{m^{2} K}{W}$ with $\mathrm{h}_{\mathrm{B} \infty}$ the heat transfer coefficient between the refractory and the environment

- $\mathrm{T}_{\infty}$ is the temperature of the environment $(\mathrm{K})$

And the energy balance equation for the refractory above the glass is:

$$
C_{W} \frac{d T_{W}}{d t}=\frac{A_{W}}{R_{G W}}\left(T_{S}-T_{W}\right)-\frac{A_{W}}{R_{W \infty}}\left(T_{W}-T_{\infty}\right)
$$


where:

- $\mathrm{C}_{\mathrm{W}}=\dot{m} c_{p W}$ the capacitance of the refractory

- $\frac{d T_{W}}{d t}$ is the time rate of change of the temperature of the refractory above the surface of the glass

- $R_{W \infty}=\frac{1}{h_{W \infty}} \frac{m^{2} K}{W}$ with $\mathrm{h}_{\mathrm{W} \infty}$ the heat transfer coefficient between the refractory and the environment

Combining like terms and dividing by capacitances gives Equations13, 14, 15, and 16 as follows:

$$
\begin{gathered}
\frac{d T_{s}}{d t}=\frac{\dot{Q}_{\text {fuel }}}{C_{s}}-\left(\frac{A_{W}}{R_{S W} C_{s}}+\frac{A_{G}}{R_{S G} C_{s}}\right) T_{S}+\left(\frac{A_{W}}{R_{S W} C_{s}}\right) T_{W}+\left(\frac{A_{G}}{R_{S G} C_{s}}\right) T_{G} \\
\frac{d T_{G}}{d t}=\left(\frac{A_{G}}{R_{S G} C_{G}}\right) T_{S}-\left(\frac{A_{G}}{R_{S G} C_{G}}+\frac{A_{B}}{R_{G B} C_{G}}\right) T_{G}+\left(\frac{A_{B}}{R_{G B} C_{G}}\right) T_{B} \\
\frac{d T_{B}}{d t}=\left(\frac{A_{B}}{R_{G B} C_{B}}\right) T_{G}-\left(\frac{A_{B}}{R_{G B} C_{B}}+\frac{A_{B}}{R_{B \infty} C_{B}}\right) T_{B}+\left(\frac{A_{B}}{R_{B \infty} C_{B}}\right) T_{\infty} \\
\frac{d T_{W}}{d t}=\left(\frac{A_{W}}{R_{G W} C_{W}}\right) T_{S}-\left(\frac{A_{W}}{R_{G W} C_{W}}+\frac{A_{W}}{R_{W \infty} C_{W}}\right) T_{W}+\left(\frac{A_{W}}{R_{W \infty} C_{W}}\right) T_{\infty}
\end{gathered}
$$


State space representation of a system has the form:

$$
\begin{aligned}
& \dot{x}=\underline{A} x+\underline{B u} \\
& y=\underline{C} x+\underline{D} u
\end{aligned}
$$

Where $\underline{\mathrm{A}}$ is the state matrix, $\underline{\mathrm{B}}$ is the input or control matrix, $\underline{\mathrm{C}}$ is the output matrix and $\underline{\mathrm{D}}$ is the feedthrough matrix. The states are the temperatures of the combustion gasses, glass, bottom refractory and wall refractory. The inputs are flame energy and environment temperature the desired output is the temperature of the glass, and noise is considered to be a zero matrix.

Equations 13-16 are arranged in state space form as follows:

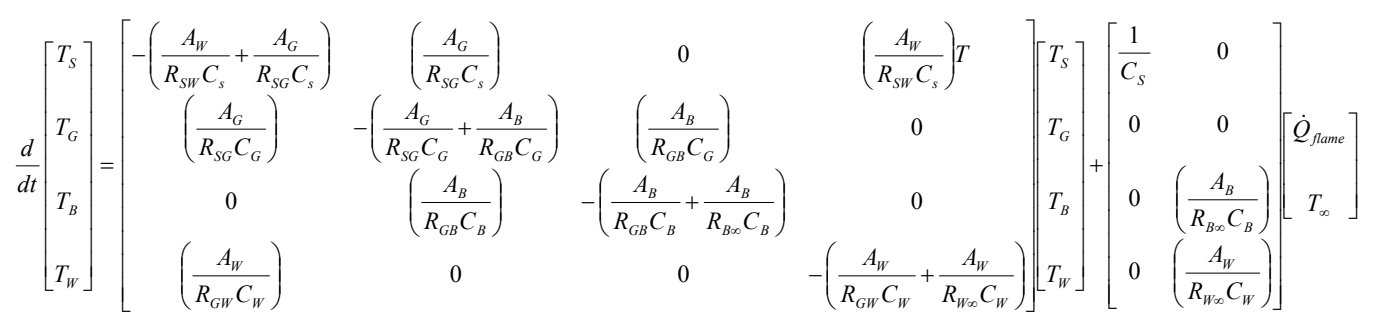

$$
y=\left[\begin{array}{llll}
0 & 1 & 0 & 0
\end{array}\right]\left[\begin{array}{c}
T_{S} \\
T_{G} \\
T_{B} \\
T_{W}
\end{array}\right]+\left[\begin{array}{ll}
0 & 0
\end{array}\right]\left[\begin{array}{c}
\dot{Q}_{\text {flame }} \\
T_{\infty}
\end{array}\right]
$$


Numeric values for the variables in the state and input matrices are needed in order to determine controllability of the system. Values were determined as follows:

Furnace area is estimated based on observations of typical glass furnaces. Furnace dimensions are shown in Table 3-1:

\begin{tabular}{|l|l|l|}
\hline Dimension & Variable & Vaule(m) \\
\hline Length & L & 1.22 \\
\hline Width & W & 1.22 \\
\hline Height & H & 0.61 \\
\hline $\begin{array}{l}\text { Glass } \\
\text { Level }\end{array}$ & X & 0.38 \\
\hline
\end{tabular}

Table 3-1: Furnace Dimensions

Area parameters shown in Table 3-2, are then:

\begin{tabular}{|l|l|}
\hline Variable & $\begin{array}{l}\text { Value } \\
\left(\mathbf{m}^{2}\right)\end{array}$ \\
\hline$A_{W}$ & 2.61 \\
\hline$A_{B}$ & 3.34 \\
\hline$A_{G}$ & 1.49 \\
\hline
\end{tabular}

Table 3-2: Area Parameters 
The mass of the combustion gas is determined using the ideal gas law,

$$
m_{S}=\frac{P_{S} V_{S}}{\underline{R}_{S} \bar{T}_{S}}
$$

with

- $\underline{R}_{S}=\frac{\underline{R}_{U}}{\bar{M} \bar{W}}=\frac{8314 \frac{\mathrm{J}}{\mathrm{kmol} \cdot \mathrm{K}}}{30.28 \frac{\mathrm{kg}}{\mathrm{kmol}}}$; the gas constant for combustion gas based on average molecular weight of stoichiometric products of methane combustion with air

- $\quad P_{S}=101325 \frac{N}{m^{2}}$; the pressure within the furnace assumed to be atmospheric for this model

- $V_{S}=0.3423 m^{3}$; the volume of the furnace containing combustion gas and

- $\quad \mathrm{T}_{\mathrm{S}}=1300 \mathrm{~K}$; the mean combustion gas temperature during operation

Combustion gas specific heat can be estimated ${ }^{7}$ as $1.025 \frac{\mathrm{KJ}}{\mathrm{Kg} \cdot \mathrm{K}}$

Capacitance for the combustion gas is then:

$$
C_{S}=m c_{p s}=0.1 \frac{\mathrm{kJ}}{\mathrm{K}}
$$


Values for glass properties have been taken from literature ${ }^{1,8}$ and are:

$$
\begin{gathered}
\rho_{G}=2.43 \frac{\mathrm{g}}{\mathrm{cm}^{3}}=2430 \frac{\mathrm{kg}}{\mathrm{m}^{3}} \\
c_{p g}=1.24 \frac{\mathrm{J}}{\mathrm{g} \cdot \mathrm{K}}=1.24 \frac{\mathrm{kJ}}{\mathrm{kg} \cdot \mathrm{K}} \text { average of data presented in }[8]^{8} \text { over the range } \\
\text { of } 1000 \mathrm{~K}-1800 \mathrm{~K}
\end{gathered}
$$

The mass of the glass is then:

$$
m_{g}=V_{G} \rho_{G}=0.566 \mathrm{~m}^{3} * 2430 \frac{\mathrm{kg}}{\mathrm{m}^{3}}=1370 \mathrm{~kg}
$$

and the capacitance of the glass is:

$$
C_{G}=m_{g} c_{p G}=1700 \frac{\mathrm{kJ}}{\mathrm{K}}
$$

Values for the density, chemical composition and thermal conductivity of the refractory are available in manufacture's literature. ${ }^{9}$ The refractory chosen for 
this model was Monofrax ${ }^{\circledR}$ CS-3 Alumina-Zirconia-Silica (AZS) Fused Cast Refractory. The density of the refractory is:

$$
\rho_{B}=\rho_{W}=3.81 \frac{\mathrm{g}}{\mathrm{cm}^{3}}=3180 \frac{\mathrm{kg}}{\mathrm{m}^{3}}
$$

The capacitance of the refractory was calculated using specific heat data for each of the major compounds in the chemical composition. The data used and calculations performed are included in Appendix A. The resulting specific heat value for the refractory is:

$$
c_{p B}=c_{p W}=1.18 \frac{\mathrm{kJ}}{\mathrm{kg} \cdot \mathrm{K}}
$$

The mass of the refractory sections are:

$$
\begin{aligned}
& m_{B}=V_{B} \rho_{B}=1.73 \mathrm{~m}^{3} * 3180 \frac{\mathrm{kg}}{\mathrm{m}^{3}}=5500 \mathrm{~kg} \\
& m_{W}=V_{W} \rho_{W}=1.45 \mathrm{~m}^{3} * 3180 \frac{\mathrm{kg}}{\mathrm{m}^{3}}=4610 \mathrm{~kg}
\end{aligned}
$$


and the capacitance values are then:

$$
\begin{gathered}
C_{B}=m_{B} c_{p B}=6500 \frac{\mathrm{kJ}}{\mathrm{K}} \\
C_{W}=m_{W} c_{p W}=5440 \frac{\mathrm{kJ}}{\mathrm{K}}
\end{gathered}
$$

Since the numeric values produced in this section are intended to be initial conditions, the resistance values for both radiation terms ( $\mathrm{R}_{\mathrm{SW}}$ and $\left.\mathrm{R}_{\mathrm{SG}}\right)$ were calculated using an initial mean temperature of $1300 \mathrm{~K}$. The resulting value is:

$$
R_{S W}=R_{S G}=\frac{1}{4 \sigma \varepsilon \bar{T}^{3}}=\frac{1}{4\left(5.67 * 10^{-8}\right)(0.3)(1300)^{3}}=0.0067 \frac{\mathrm{m}^{2} \mathrm{~K}}{\mathrm{~W}}=6.7 \frac{\mathrm{m}^{2} \mathrm{~K}}{\mathrm{~kW}}
$$

The resistance between the refractory and the environment was calculated from surface conductance values available in literature. ${ }^{10}$ The resistance values are:

$$
R_{B \infty}=R_{W \infty}=\frac{1}{0.00721}=139 \frac{\mathrm{m}^{2} \mathrm{~K}}{\mathrm{~kW}}
$$


The resistance term between the molten glass and the refractory was assumed to be roughly equivalent to the contact resistance between molten glass and a mold during a forming process ${ }^{11}$. The value is then:

$$
R_{G W}=\frac{1}{500}=0.002 \frac{\mathrm{m}^{2} \mathrm{~K}}{W}=2.0 \frac{\mathrm{m}^{2} \mathrm{~K}}{\mathrm{~kW}}
$$

A summary of the terms is given in Table 3-3.

\begin{tabular}{|c|c|c|}
\hline Variable & Value & Units \\
\hline $\mathbf{A}_{\mathbf{w}}$ & 2.61 & \multirow{3}{*}{$m^{2}$} \\
\hline $\mathbf{A}_{\mathbf{B}}$ & 3.34 & \\
\hline $\mathbf{A}_{\mathbf{G}}$ & 1.49 & \\
\hline $\mathrm{C}_{\mathrm{S}}$ & 0.1 & \multirow{4}{*}{$\frac{k J}{K}$} \\
\hline $\mathrm{C}_{\mathrm{G}}$ & 1700 & \\
\hline $\mathbf{C}_{\mathbf{B}}$ & 6500 & \\
\hline$\overline{C_{W}}$ & 5450 & \\
\hline $\mathbf{R}_{\text {SW }}$ & 6.7 & \multirow{5}{*}{$\frac{m^{2} K}{k W}$} \\
\hline $\mathbf{R}_{\mathrm{SG}}$ & 6.7 & \\
\hline $\mathbf{R}_{\mathbf{B}} \infty$ & 139 & \\
\hline $\mathbf{R}_{\mathbf{W} \infty}$ & 139 & \\
\hline $\mathbf{R}_{\mathbf{G B}}$ & 2 & \\
\hline
\end{tabular}

Table 3-3: Numeric Values for Matrix Terms 
The state space form now appears as:

$$
\begin{aligned}
& \frac{d}{d t}\left[\begin{array}{c}
T_{S} \\
T_{G} \\
T_{B} \\
T_{W}
\end{array}\right]=\left[\begin{array}{cccc}
-6.14 & 2.23 & 0 & 3.91 \\
1.31 E-4 & -1.11 E-3 & 9.83 E-4 & 0 \\
0 & 2.57 E-4 & -2.61 E-4 & 0 \\
7.16 E-5 & 0 & 0 & -7.5 E-5
\end{array}\right]\left[\begin{array}{c}
T_{S} \\
T_{G} \\
T_{B} \\
T_{W}
\end{array}\right]+\left[\begin{array}{cc}
10 & 0 \\
0 & 0 \\
0 & 3.7 E-6 \\
0 & 3.45 E-6
\end{array}\right]\left[\begin{array}{c}
\dot{Q}_{\text {flame }} \\
T_{\infty}
\end{array}\right] \\
& y=\left[\begin{array}{llll}
0 & 1 & 0 & 0
\end{array}\right]\left[\begin{array}{c}
T_{S} \\
T_{G} \\
T_{B} \\
T_{W}
\end{array}\right]+\left[\begin{array}{ll}
0 & 0
\end{array}\right]\left[\begin{array}{c}
\dot{Q}_{\text {flame }} \\
T_{\infty}
\end{array}\right]
\end{aligned}
$$

The first step in control design is to determine if the system is controllable and/or observable. The controllability matrix is formed by:

$$
\underline{\mathrm{P}}=\left[\underline{\mathrm{B}} \underline{\mathrm{AB}} \underline{\mathrm{A}^{2}} \underline{\underline{B}} \underline{A}^{3} \underline{B}\right]
$$

and the observability matrix is formed by:

$$
\underline{Q}=\left[\underline{\mathrm{C}} \underline{\mathrm{CA}} \underline{\mathrm{CA}}^{2} \underline{\mathrm{CA}}^{3}\right]^{\mathrm{T}}
$$

The MATLAB commands "ctrb(A,B)" and "obsv(A,C)" were used to find the controllability and observability matrices. The matrix $\underline{\mathrm{P}}$ must be fully ranked 
for the system to be controllable and the matrix $\underline{Q}$ must be fully ranked for the system to be observable. The MATLAB command "rank()" was used to find the rank of $\underline{P}$ and $\underline{Q}$. The matrices were found to have a rank of 4 and the system was determined to be both controllable and observable. Maps of the pole locations are shown in Figure 3-C and Figure 3-D.

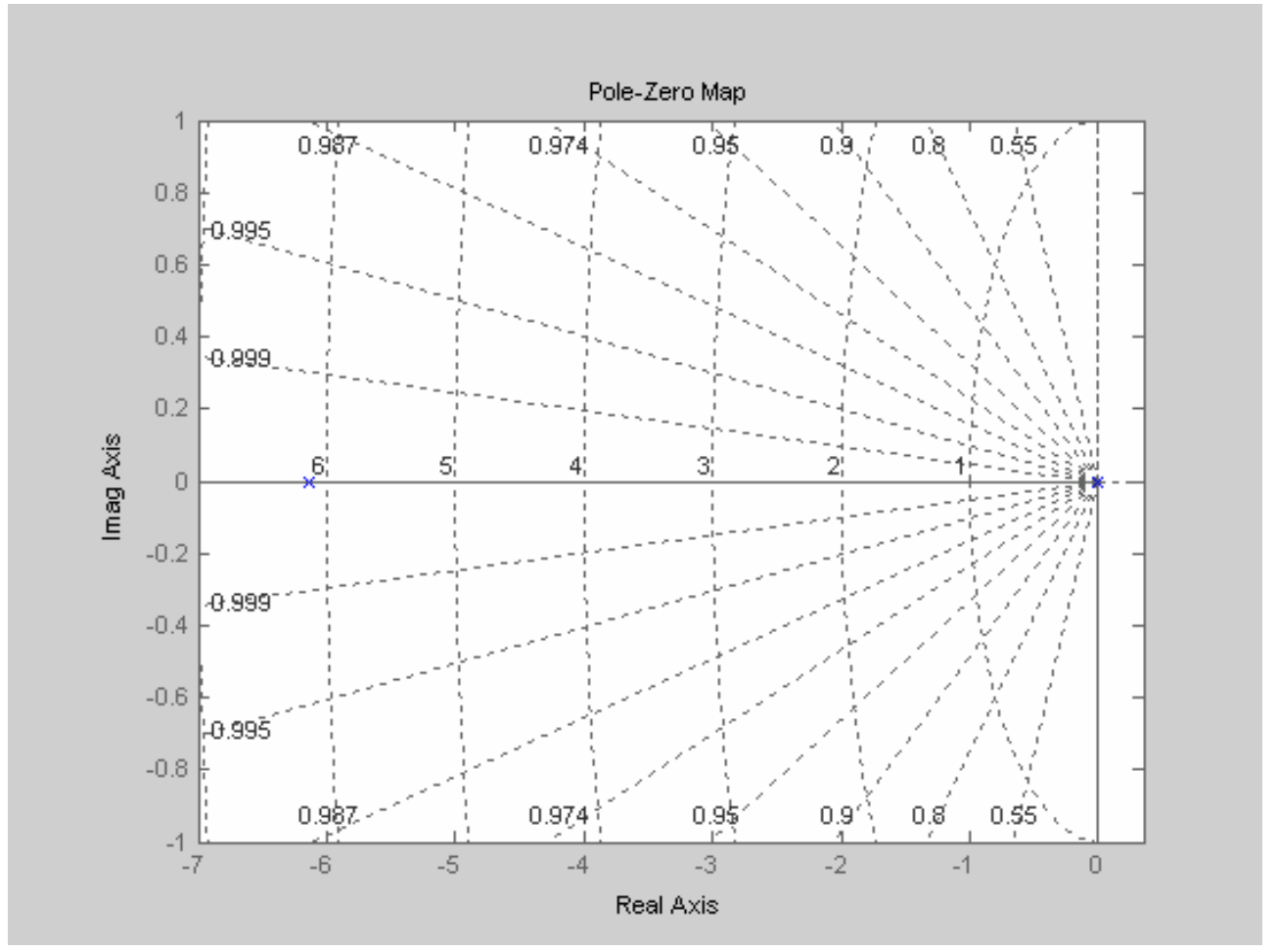

Figure 3-C: Pole-Zero Map of Open Loop Poles 


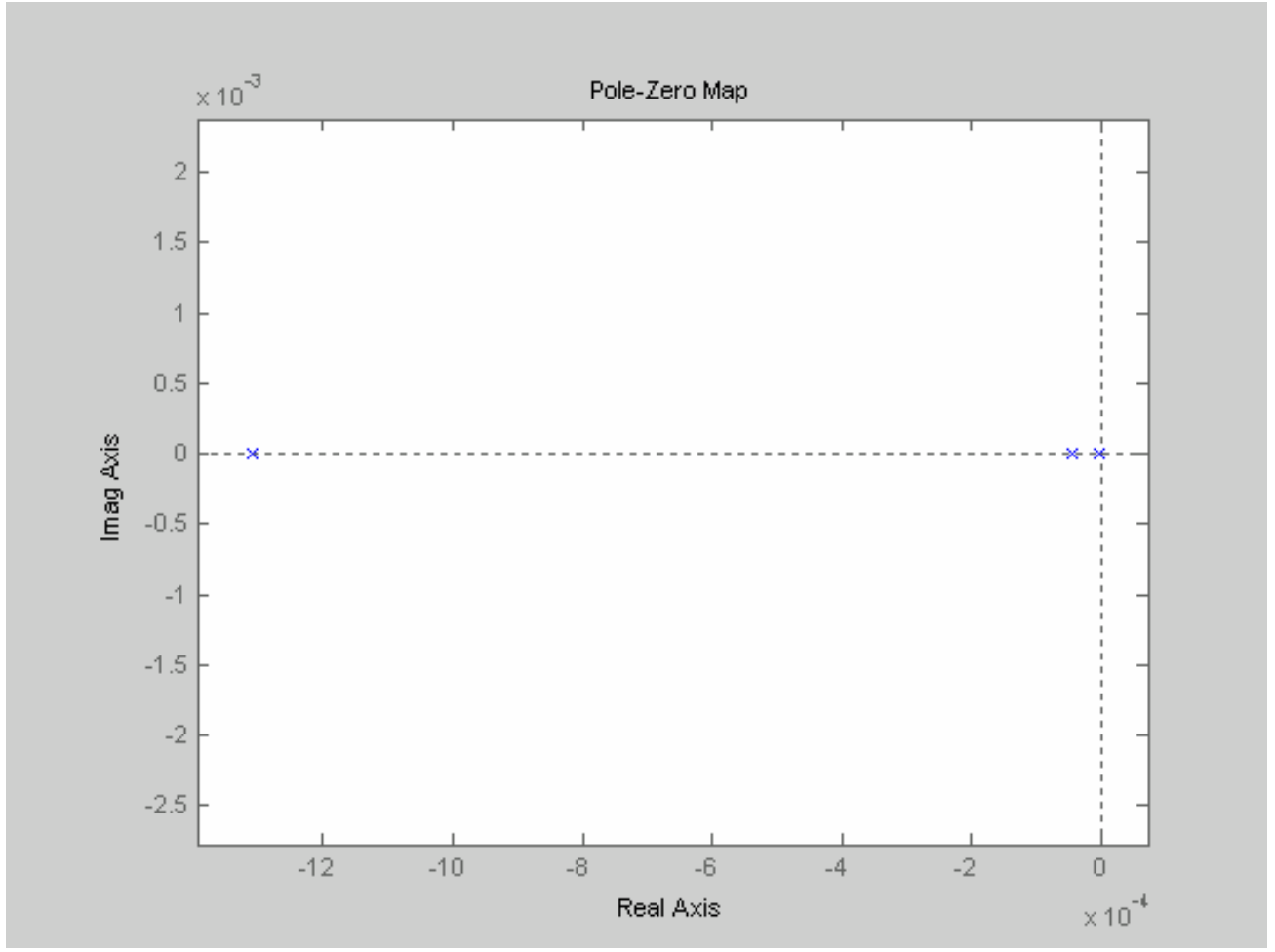

Figure 3-D: Pole Zero Map of Open Loop Poles Close to Zero 


\section{VALIDATION OF MODEL}

A Simulink model was created using the parameters developed in Chapter 3. This model will be used to represent the "true" system to which the parameter estimates supplied by the observer will be compared. The Simulink model is shown in Figure 4-A

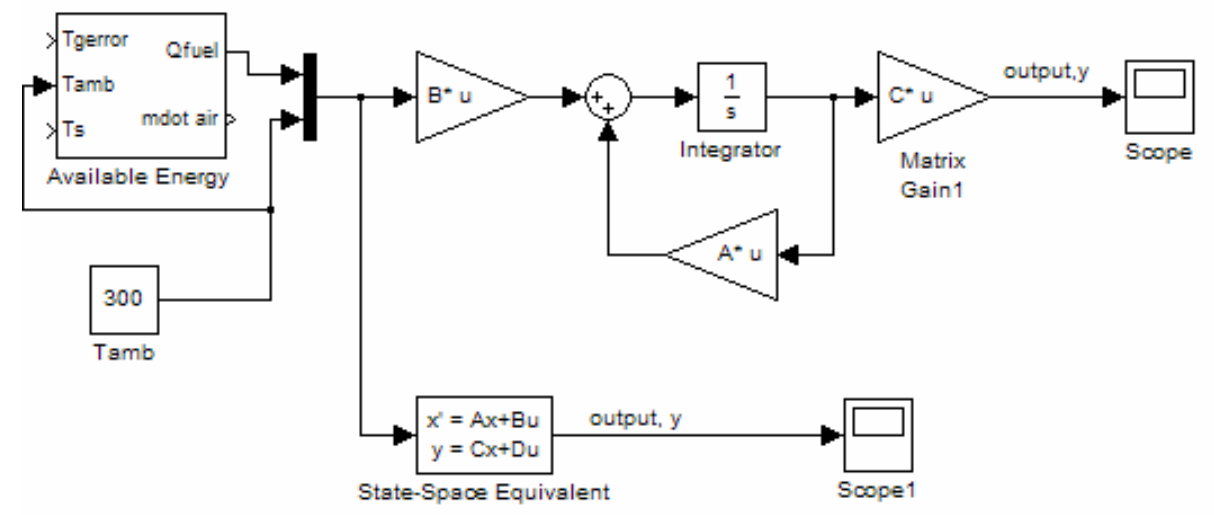

Figure 4-A: Simulink Model

The inputs to the model are the ambient temperature surrounding the furnace and the fuel energy per unit time. The ambient temperature was held constant for all simulations at $300 \mathrm{~K}$. The desired energy input, shown as the output Qfuel from the Available Energy subsystem, was made proportional to the 
difference between the glass temperature output and the desired glass temperature as follows:

- The furnace modeled operates using a single 2.5 MMBtu/hour burner. For natural gas at $1000 \mathrm{Btu} / \mathrm{ft}^{3}$, this is equivalent to a volumetric flow rate of $2500 \mathrm{ft}^{3} / \mathrm{hr}$ or $0.02 \mathrm{~m}^{3} / \mathrm{second}$.

- The specific gravity of methane (referenced to air) is 0.55 . The resulting density is $0.67 \mathrm{~kg} / \mathrm{m}^{3}$. The maximum mass flow rate of fuel to this burner is then $0.013 \mathrm{~kg} / \mathrm{sec}$.

- The energy available to the process is a function of the mass flow rate of fuel, air/fuel ratio, flame and ambient temperatures, heating value of the fuel and the specific heat of the combustion products. The relationship between ideal energy from the fuel and energy available to the process was derived is shown below. 


$$
\begin{gathered}
\dot{Q}_{\text {fuel }}=\dot{Q}_{\text {comb }}-\dot{Q}_{\text {loss }} \\
\dot{Q}_{\text {comb }}=\dot{m}_{\text {fuel }} * L H V \\
\dot{Q}_{\text {loss }}=\dot{m}_{\text {fuel }}(1+A / F) * c_{p s}\left(T_{s}-T_{\infty}\right) \\
\dot{Q}_{\text {fuel }}=\dot{m}_{\text {fuel }}\left(L H V-(1+A / F) * c_{p s}\left(T_{s}-T_{\infty}\right)\right)
\end{gathered}
$$

where:

- $\dot{Q}_{\text {comb }}$ is the energy available from combustion

- $\dot{\mathrm{Q}}_{\text {loss }}$ is the stack energy loss

- $\dot{Q}_{\text {fuel }}$ is the energy available to the process

with

- LHV the lower heating value of methane $(49770 \mathrm{~kJ} / \mathrm{kg})$

- $A / F$ is the air fuel ratio. The stoichiometric value of 17.2 was used for the simulations 
- $c_{p s}$ is the approximated specific heat of the combustion products used in Chapter 3

- $T_{s}$ is the measured temperature of the combustion (stack) gasses

- $T_{\infty}$ is the ambient temperature of the plant

Equation (20) is illustrated in the Simulink subsystem Available Energy shown in Figure 4-B.

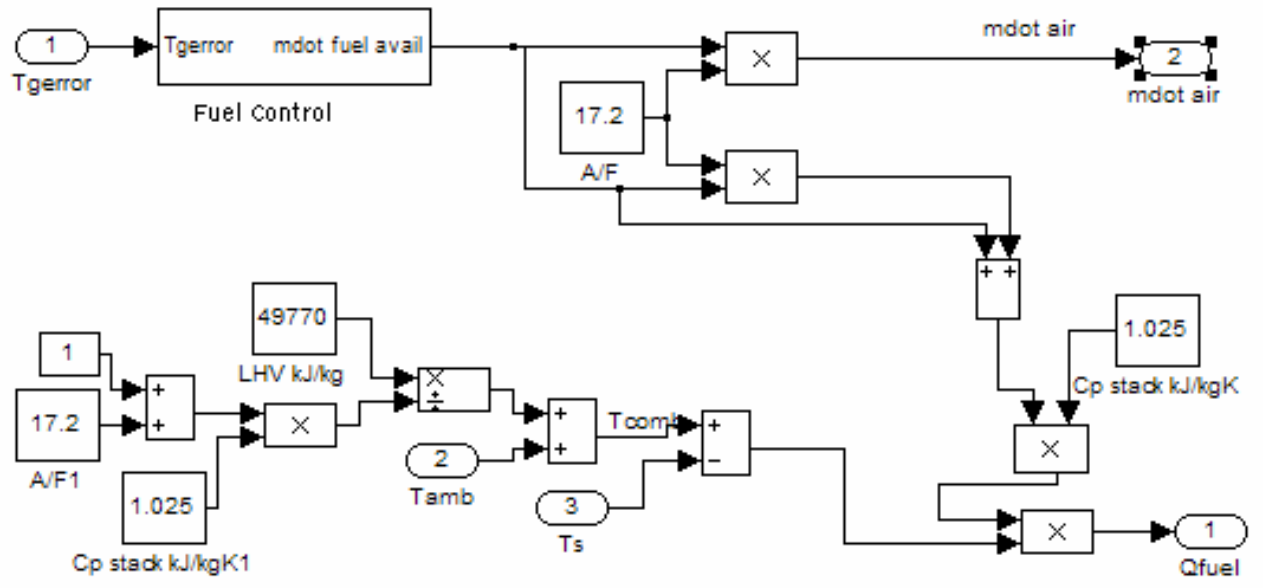

Figure 4-B: Available Energy to Furnace 
The Fuel Control Subsystem contains the control law for the furnace. The mass flow rate of fuel used in simulations was made proportional to the difference between the calculated glass temperature and the desired glass temperature, $\Delta \mathrm{T}$, using the following relationship:

$$
\dot{m}_{f u e l}=\dot{m}_{\max }\left(1-e^{-0.04 \Delta T}\right)
$$

The small time constant was chosen to represent the burner running at or near maximum capacity unless the temperature of the glass is very close (within 50 degrees) to that of the set point.

To verify that the developed parameters provide a valid representation of glass furnace response during operation, several simulations were performed. First, a simulation was run to compare the time response of the glass temperature to the energy input. This simulation represents the melting period of the glass from $300-1500 \mathrm{~K}\left(80-2240^{\circ} \mathrm{F}\right)$. The simulation shows that it takes about 21 hours to heat the glass from room temperature to working temperature when the furnace structure is also at room temperature (cold start) and about 11 hours to heat the glass to working temperature when the furnace has been heated to $1000 \mathrm{~K}$ (hot start). The plots are shown in Figure 4-C and Figure 4-D. 


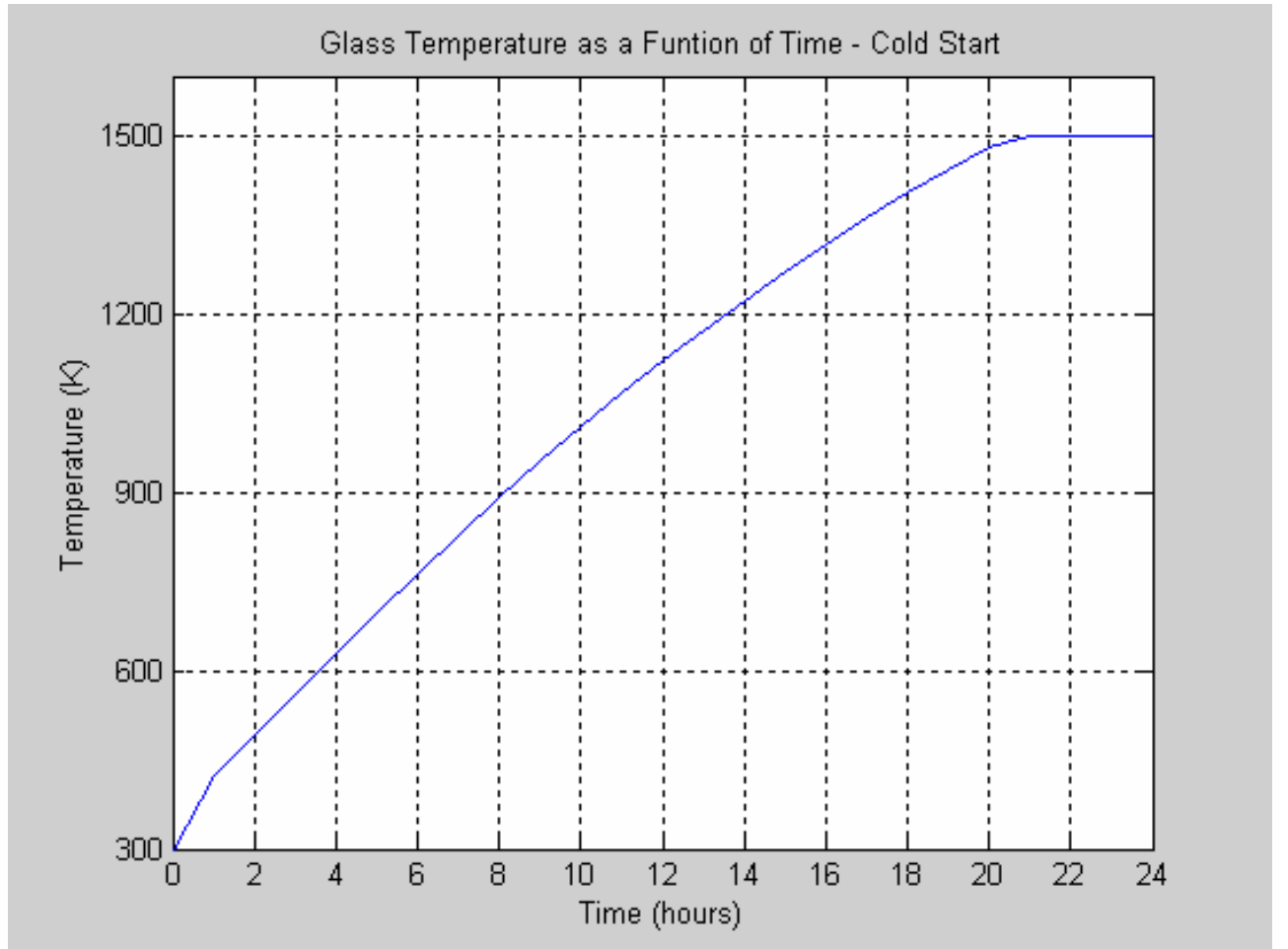

Figure 4-C: Temperature of Glass Over Time - Cold Start

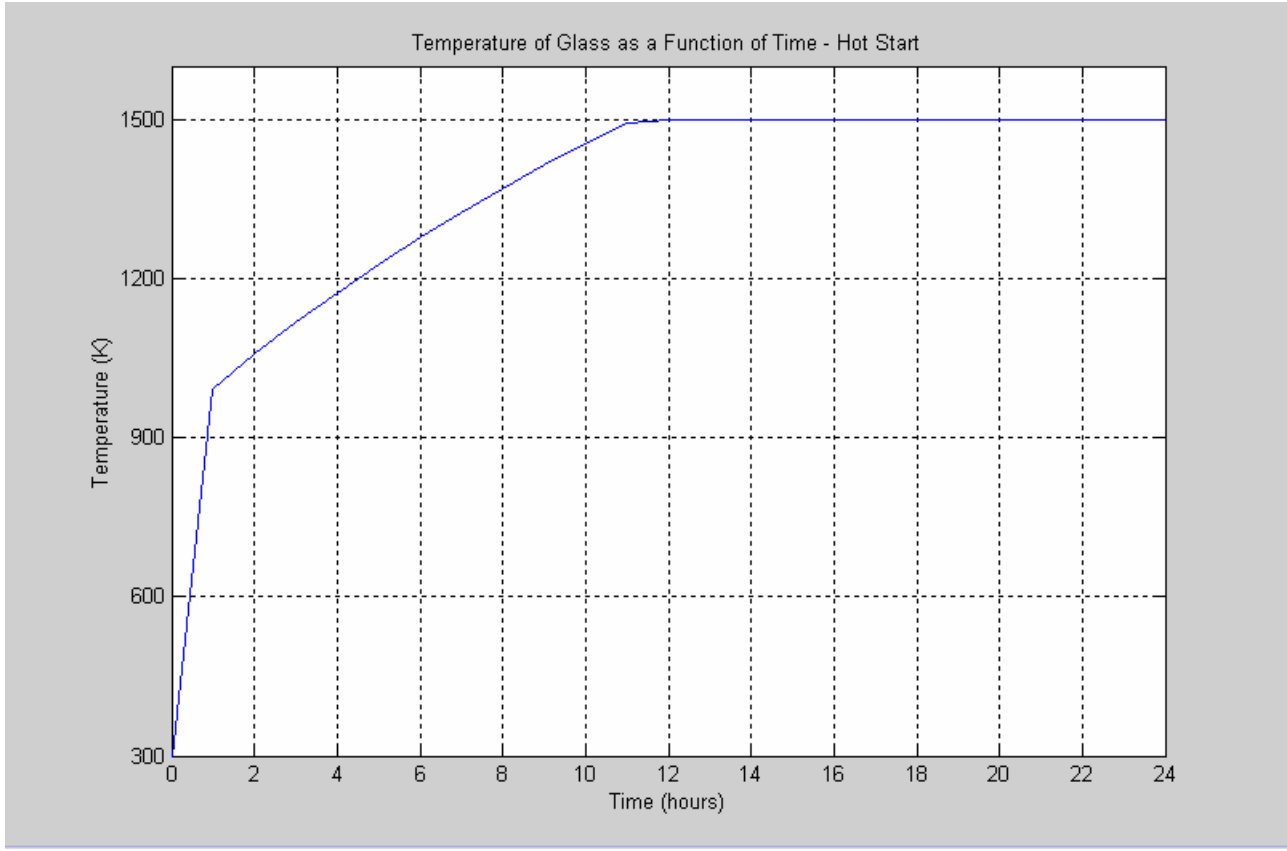

Figure 4-D: Temperature of Glass Over Time - Hot Start 
The much slower response of the cold furnace simulation shows the effect of the large capacitance of the refractory in contact with the glass. The available energy must first heat the glass and then the energy in the glass can heat the refractory. The time response of the refractory in contact with the glass in a cold start simulation is shown in Figure 4-E.

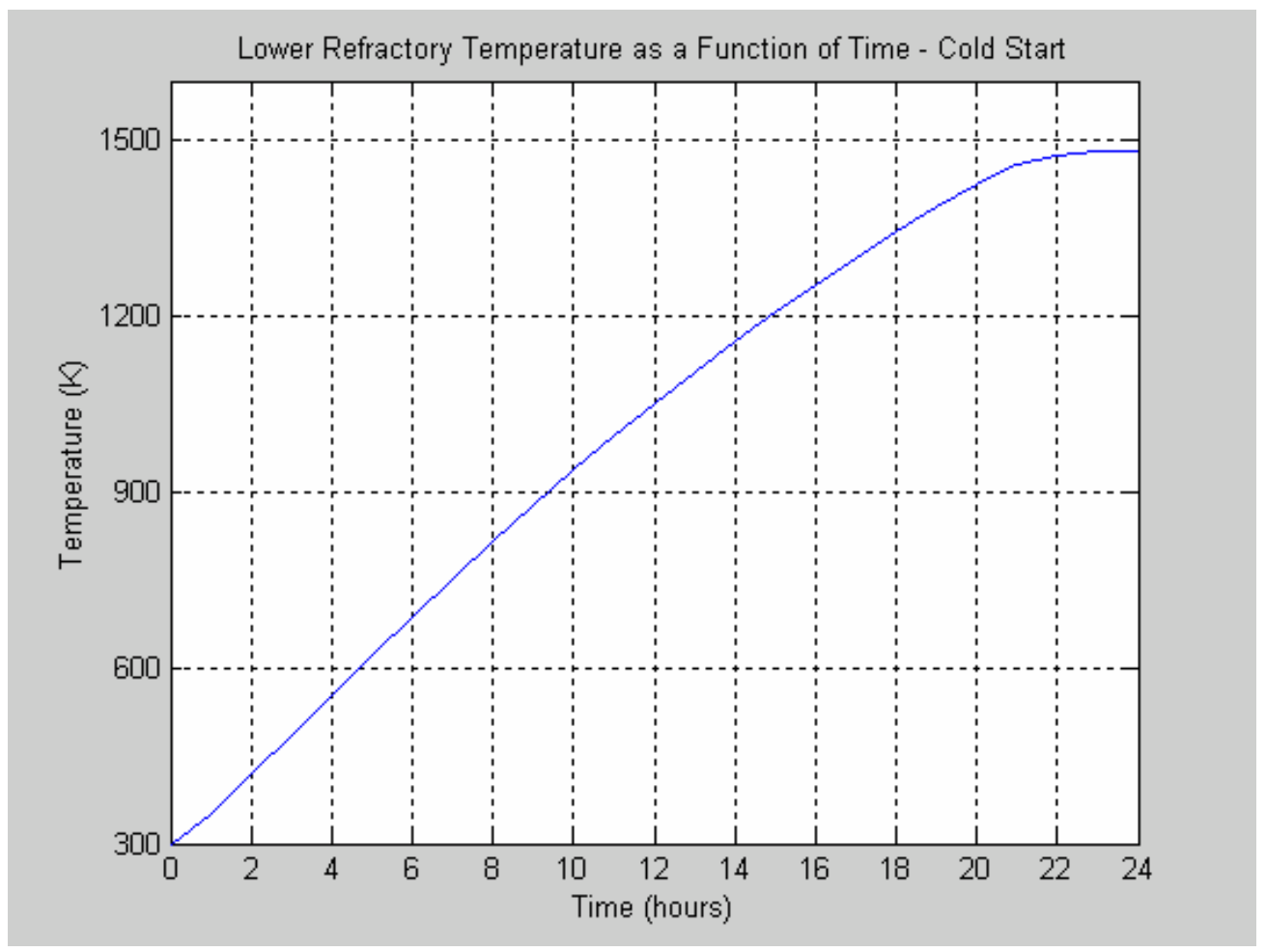

Figure 4-E: Response of Refractory Temperature for Cold Furnace 
This plot shows that the model accurately simulates the slow temperature increase due to the large capacitance of the bottom refractory. Cold start situations are not seen in practice because thermal shock would destroy the refractory. Instead, a small burner is placed in the mouth of the furnace and the refractory is heated over a period of several days. The purpose of the cold start simulation is strictly to emphasize the effect of the slow thermal response of the refractory.

Because the model does not compensate for evaporative or enthalpy losses due to water in the batch materials and volatile chemical reactions during phase changes of the batch components and since the constants used in constructing the model were based on mean values over a temperature range of $1000-1800 \mathrm{~K}$, calculations for lower temperatures are not expected to be as accurate. For these reasons, simulations for estimation purposes will be under hot start conditions. An additional constraint, setting the initial glass temperature to $1000 \mathrm{~K}$, is included for the same reasons. Figure 4-F shows the response time of the glass temperature from $1000-1500 \mathrm{~K}$ is approximately 10 hours. 


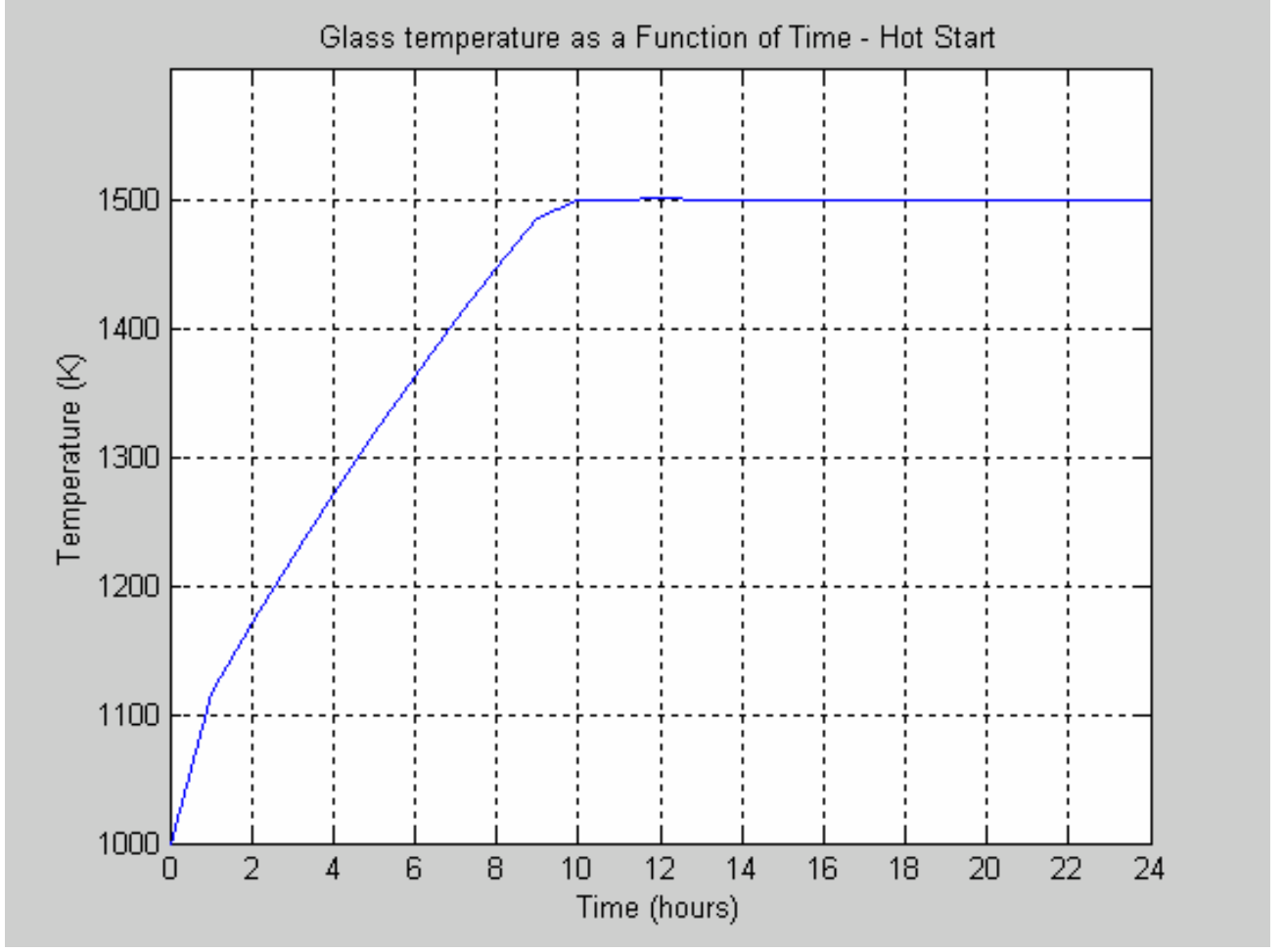

Figure 4-F: Glass Temperature as a Function of Time - Hot Start

Because these values were determined to be reasonable estimates of batch melting time when compared to times provided by industry personnel, the model was considered to provide valid estimates of furnace dynamics for the purpose of this thesis. 


\section{CONTROL APPROACH}

\subsection{Problems with Current Techniques}

Trying to control glass temperature based on an error in the combustion gas temperature does not work well because there is no direct relationship between the two temperatures. Plots of all calculated states and the mass flow rate of fuel are shown in Figure 5-A and Figure 5-B on the following page.

Figure 5-A shows that there is a large difference between the ratio of gas and glass temperatures during melting conditions and working conditions. Unless the glass temperature is measured, the point at which the fuel flow rate must be cut back is unknown. Currently, this cut off point is determined by a combination of "rule of thumb" melting times and crude methods of temperature approximation. One such method is the "stick" method by where an iron rod is dipped into the molten glass and then removed. Some of the glass clings to the cold rod and an operator judges the glass temperature by the apparent viscosity of the glass dripping from the rod. These types of control methods often result in excess fuel usage to due overheating of the glass melt. 


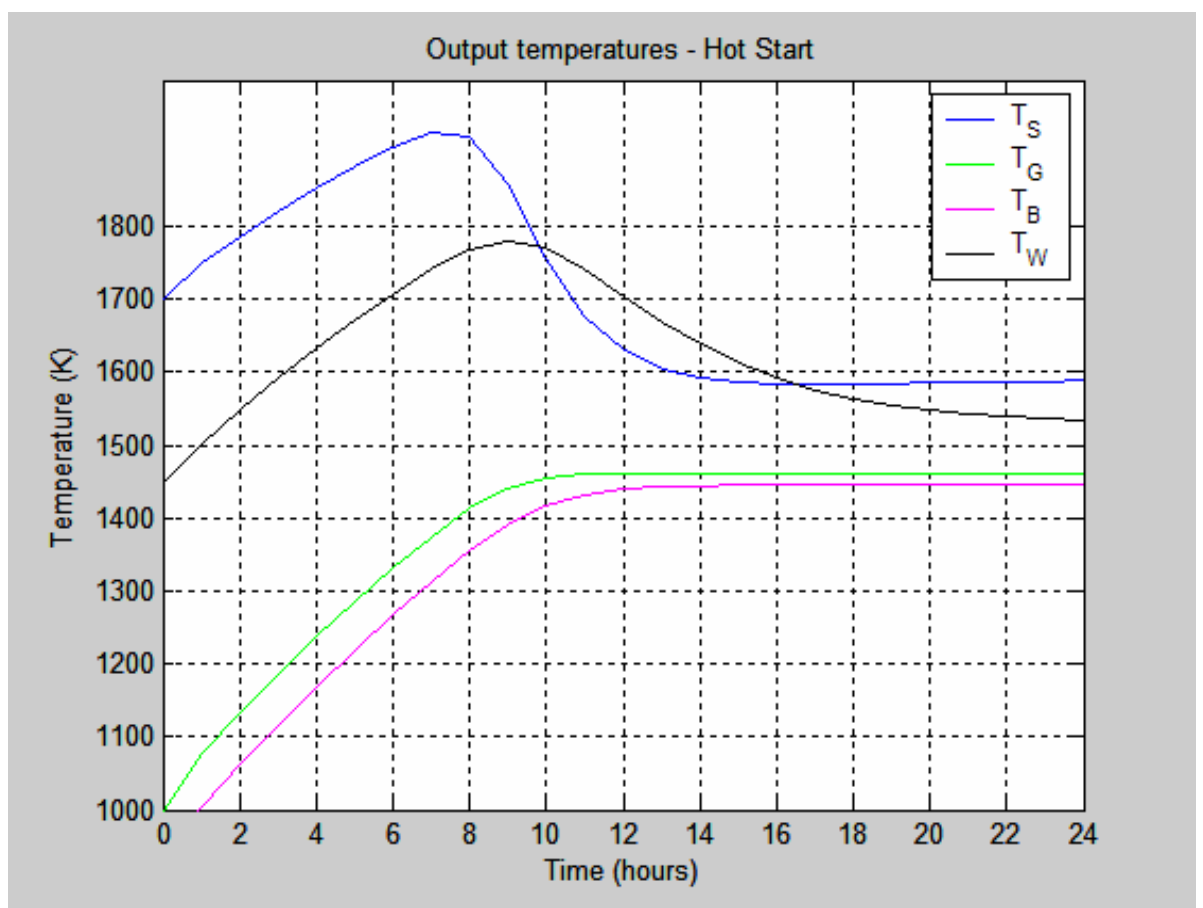

Figure 5-A: Calculated Output Temperatures

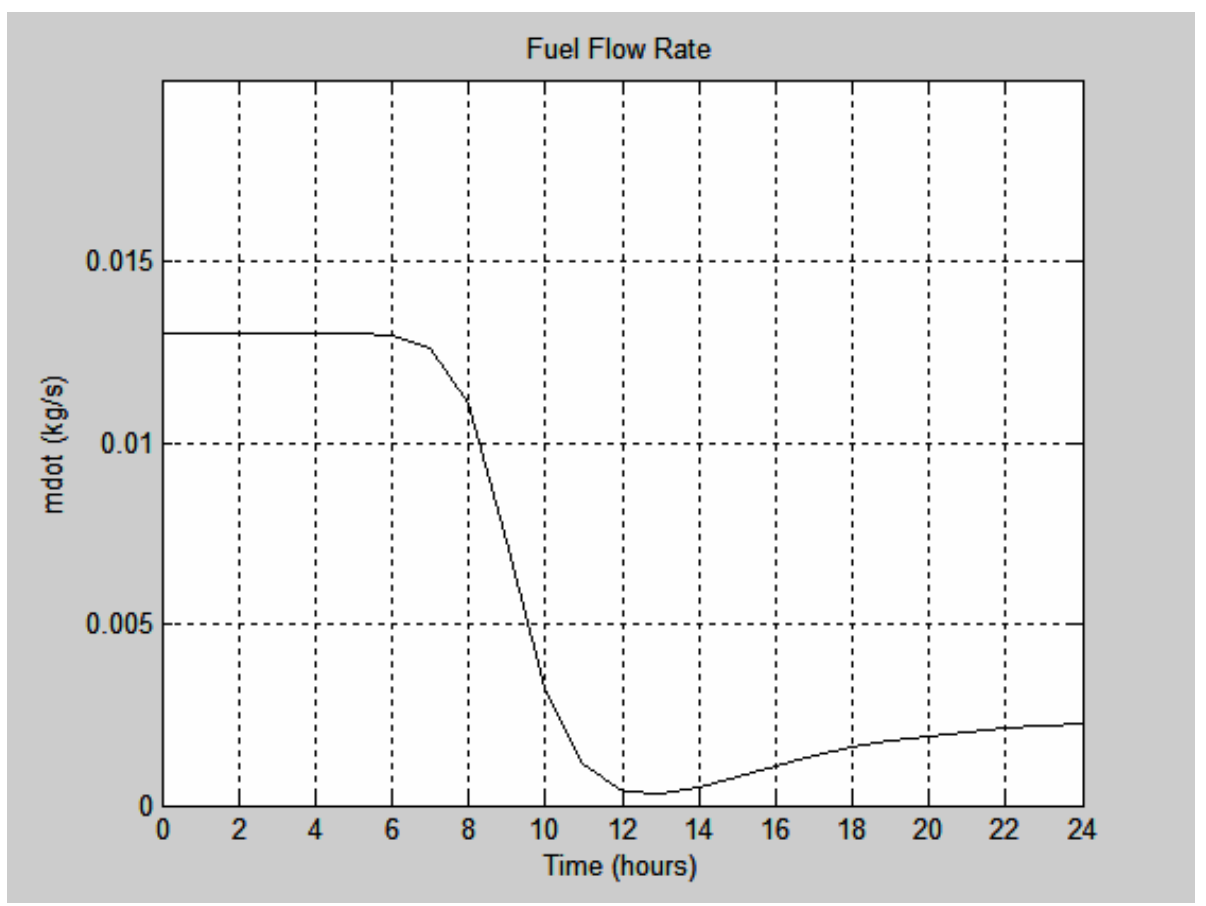

Figure 5-B: Fuel Flow Rate 
Setting the control set point to an estimated steady state value is also ineffective and results in excessively long melt times as shown in Figure 5-C.

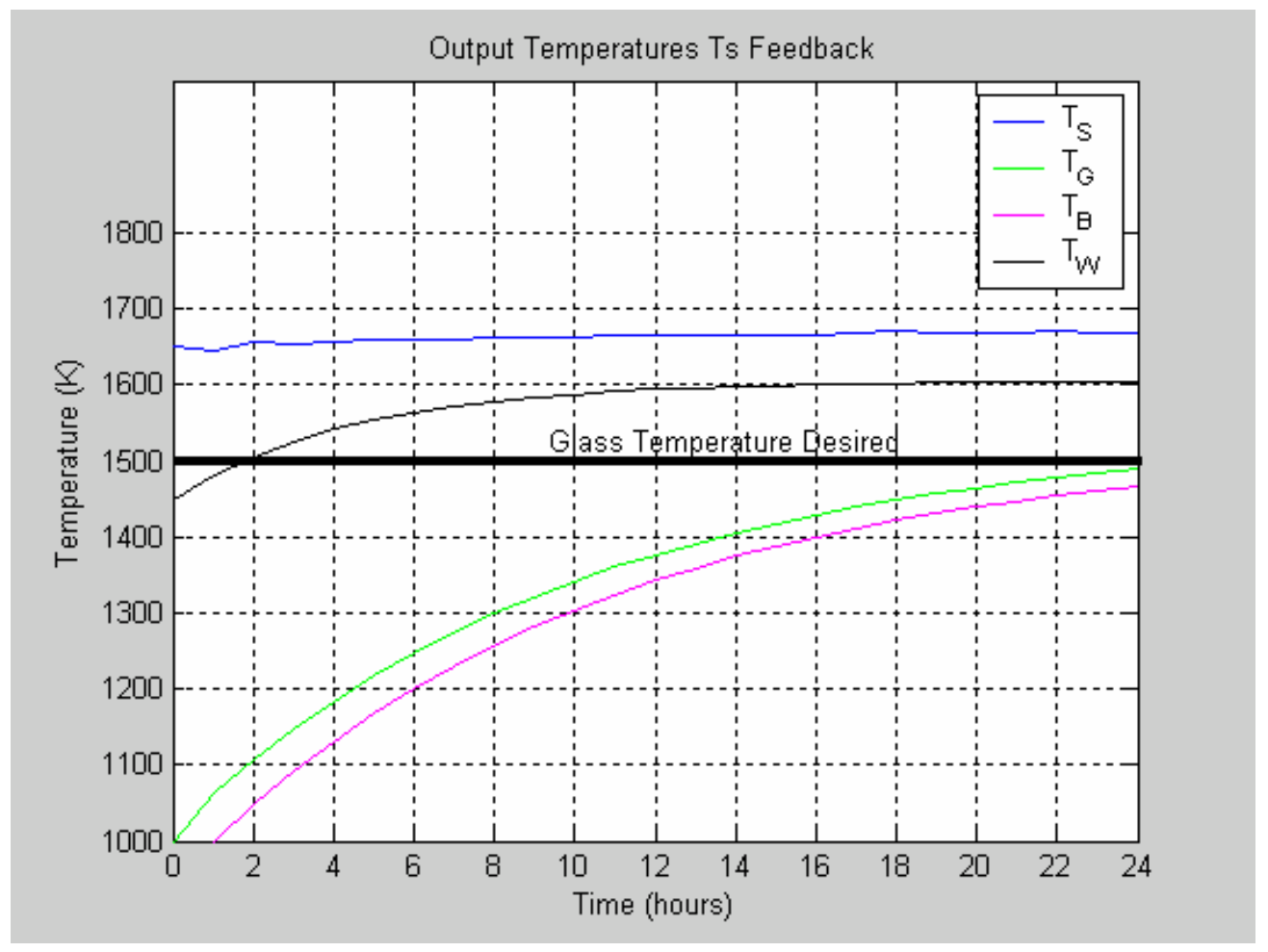

Figure 5-C: Response Time with Ts Used as Feedback

Increasing the $T_{S}$ set point decreases the response time of the glass (Figure 5-D) but the time at which the set point should be reduced to maintain desired glass temperature is still unknown. 


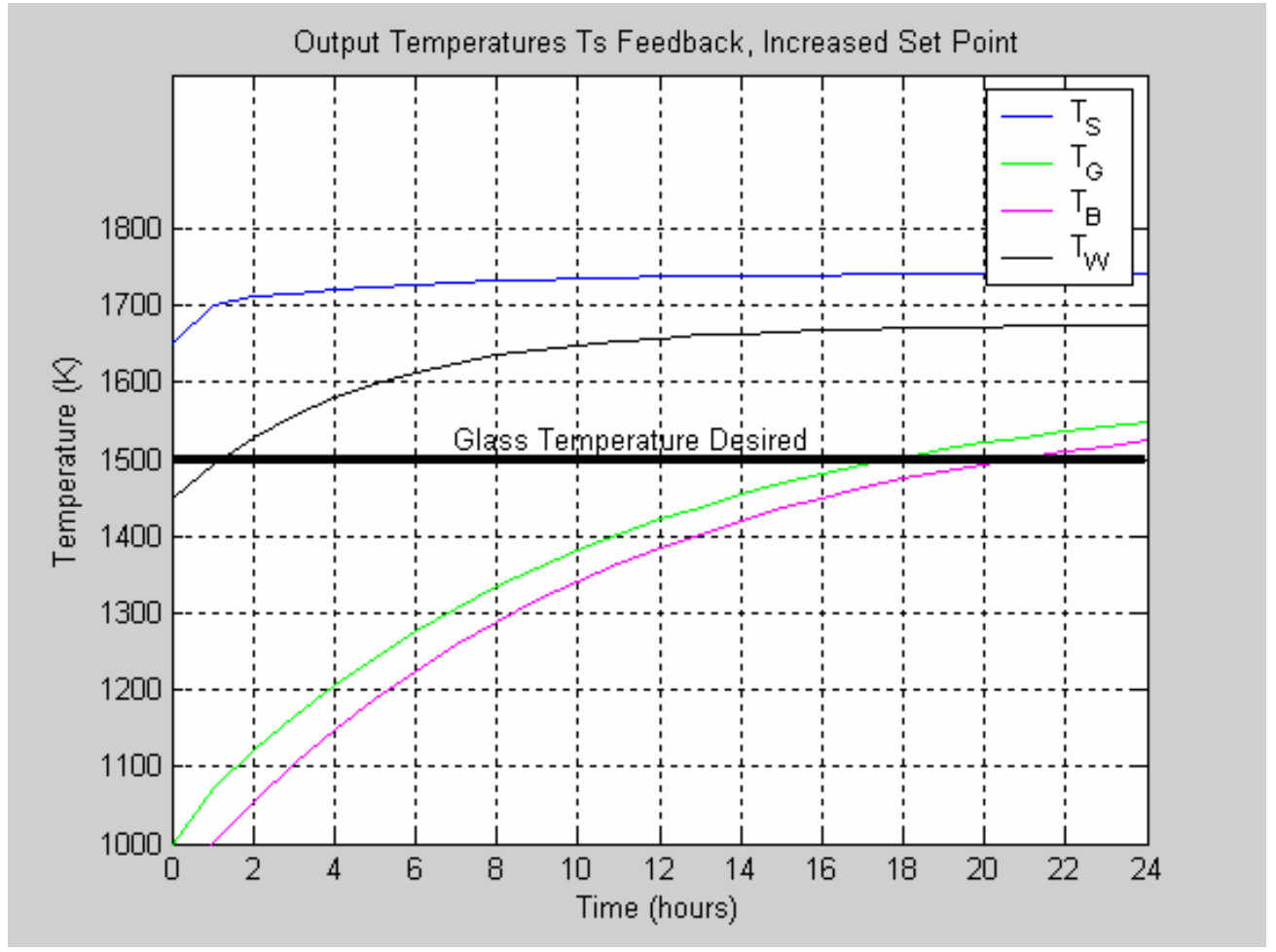

Figure 5-D: Increased Set Point For Ts

Even if the long time response were acceptable, other factors can influence the glass temperature.

\subsubsection{Glass Removal Disturbance}

Operational procedures can produce additional inputs to the system that disturb the normal system dynamics. Disturbance inputs vary by situation but for the purpose of this thesis, the disturbance input is modeled after the periodic removal of glass from the furnace for the purpose of forming. This 
disturbance consists of opening the gathering port door and putting a heavy metal rod or ladle into the melt to extract a "gob" of glass. The gathering implement is cooled before it is inserted into the melt, and thus constitutes an energy loss from the melt. The noise signal used to represent the disturbance input was a periodic square pulse whose magnitude was based on a $10 \mathrm{~kg}$ ladle entering the melt at ambient temperature and being heated to $1000 \mathrm{~K}$ in the process of glass extraction.

Figure 5-E shows the effect of glass removal on the temperature of the glass in the furnace when the measured $T_{S}$. is used for feedback to the controller. For this simulation, the temperatures were allowed to reach and remain at steady state conditions for 2 hours. Then, the disturbance input described above was added to the simulation for a period of 3 hours. The disturbance was then removed and the simulation continued for a total of 24 hours. The plot shows that the glass temperature decreases over 20 degrees over the period of glass removal even though Ts remains at the set point. 


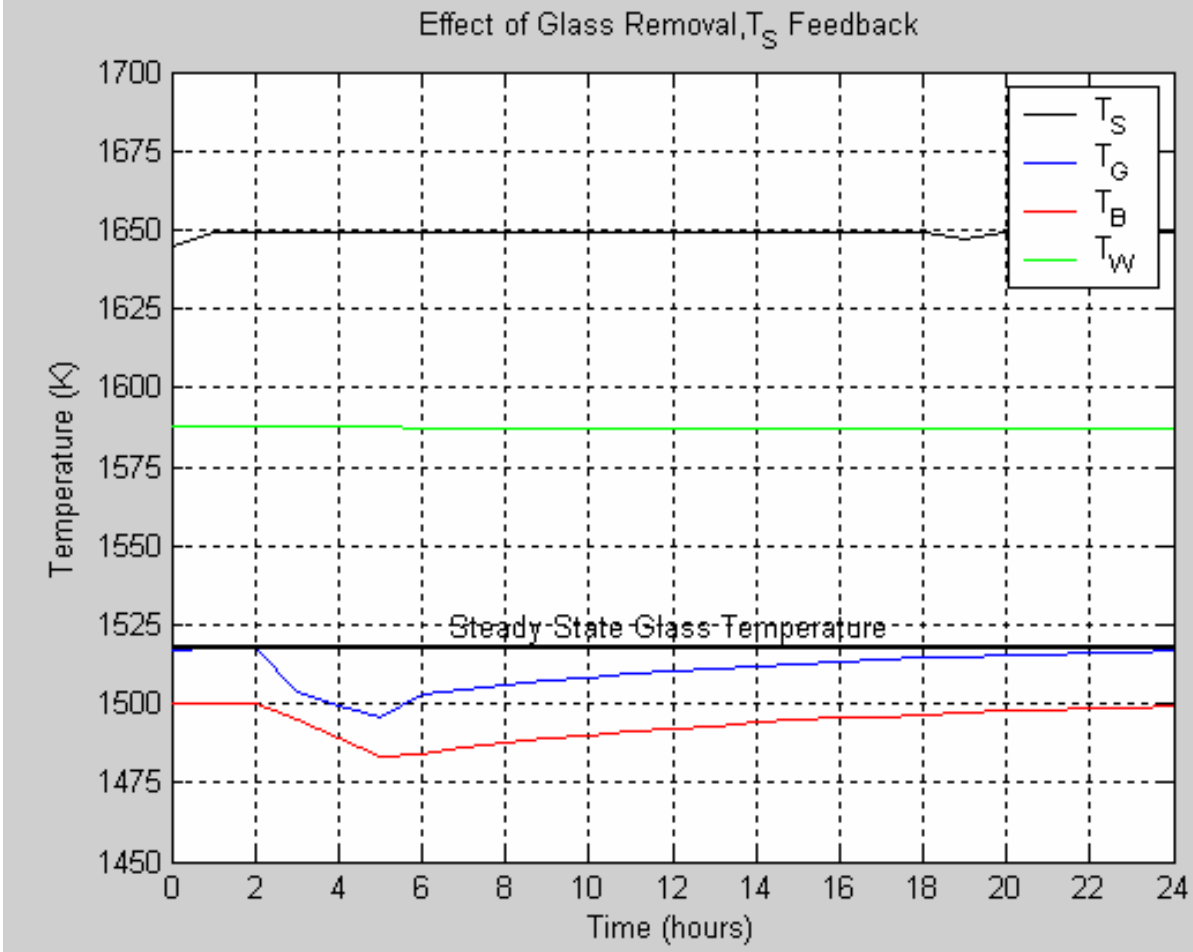

Figure 5-E: Effect of Glass Removal on $T_{G}$, $T_{S}$ Feedback

Having access to the glass temperature as a feedback parameter would be an ideal situation for controlling the furnace. Measuring the glass temperature would eliminate the problems with rule of thumb melting times, inaccurate temperature estimation methods, and disturbance effects. However; existing technology, such as IR temperature sensors, as well as the systems required to support them are expensive. Infra-red temperature sensing systems capable of the necessary range cost in the order of $\$ 10-12,000$ per furnace to implement. ${ }^{12}$ The sensors must be protected from high process temperatures, 
usually with a compressed air supply, adding to the maintenance cost of the system. Because the expense of implementing a system to measure the glass temperature directly would not be feasible for a small glass company, a better method of estimating the glass temperature must be devised.

\subsection{Suggested Solution}

Observers are a mathematical method of estimating the states of a system. Observers use the measured states of the system and known or reasonably accurate system dynamics along with known control inputs to provide estimates of the unknown or immeasurable states. The mathematical model of an observer is basically the same as that of the observed system except for the addition of a feedback term. Feedback to the observer is the estimation error - the difference between the measured output and the estimated output, used to compensate for inaccuracies in the plant matrices, A and B, and the unknown initial error. For a plant described by

$$
\begin{aligned}
& \dot{x}=\underline{A} x+\underline{B} u \\
& y=\underline{C} x
\end{aligned}
$$


The observer can be defined as:

$$
\dot{\hat{x}}=\underline{A} \hat{x}+\underline{B} u+\underline{L}(y-\underline{C} \hat{x})
$$

Where $\dot{\hat{x}}, \hat{x}$, and $\underline{\mathrm{L}}$ are, respectively, the time rate of change of the estimated state vector, the estimated state vector and the observer gain matrix.

Estimation error, $e=(x-\hat{x})$, can be shown as (21)- (22):

$$
\begin{aligned}
& \dot{e}=\dot{x}-\dot{\hat{x}}=\underline{A} x-\underline{A} \hat{x}+\underline{B} u-\underline{B} u-\underline{L}(\underline{C} x-\underline{C} \hat{x}) \\
& \dot{e}=\underline{A}(x-\hat{x})-\underline{L C}(x-\hat{x})=(\underline{A}-\underline{L C})(x-\hat{x})=(\underline{A}-\underline{L C}) e
\end{aligned}
$$

It is desired to drive the error to zero so that at steady state operation, the estimated states are equal to the actual states. This is accomplished by choosing the eigenvalues of the closed loop observer equation, ($\underline{\mathrm{A}}-\underline{\mathrm{LC}})$, such that the response of the observer is stable and the error vector will converge to zero fast enough to provide adequate estimates of the unknown states to the plant. The desired response characteristics can be converted into desired pole locations, (eigenvalues), typically chosen to be 2-5 times faster than the poles of the observed plant. After choosing desired pole locations, methods such as Ackermann's formula ${ }^{13}$ can be used to calculate the observer gain matrix. A Simulink block diagram of an observer is shown in Figure 5-F. 


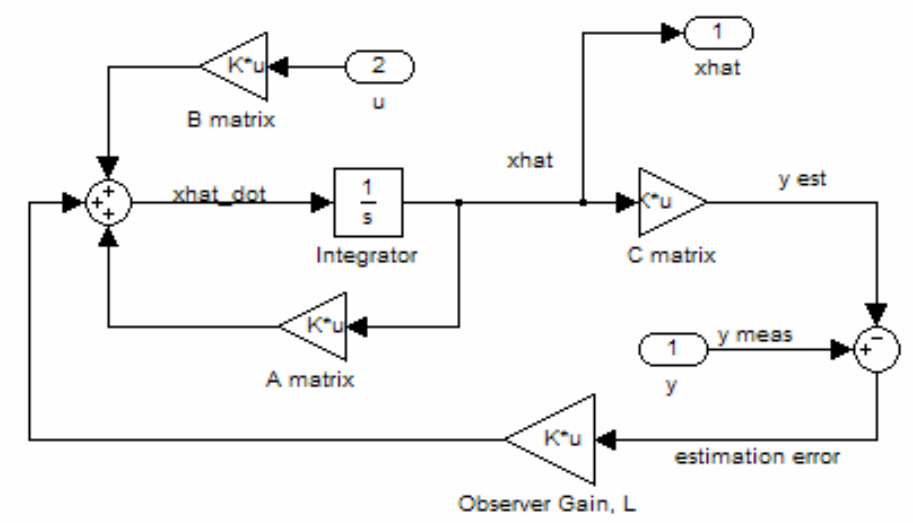

Figure 5-F: Simulink Block Diagram of Observer

The following sections show how an observer can be employed to estimate the glass temperature and provide feedback for the furnace control system.

\section{Observer Based on Gas Temperature Measurement}

An observer was designed to determine the feasibility of estimating the glass temperature based on the currently available measurement of combustion gas temperature. The eigenvalues of the A matrix are $-6.143-0.001-3.1 \mathrm{E}-6$ and $-4.4 \mathrm{E}-5$. The matrix $\left[\begin{array}{llll}1 & 0 & 0 & 0\end{array}\right]$ was used for the $\underline{\mathrm{C}}$ matrix of the observer so that only the error in combustion gas temperature would be fed back for estimation error. The desired pole locations were chosen by trial and error as a 
compromise between observer stability and response time. The MATLAB command 'place' was used to calculate the observer gain matrix.

- The best results were found with desired pole locations at $\left[\begin{array}{llll}-10 & -0.1 & -0.005 & -0.005\end{array}\right]$.

- The gains were then $\left[\begin{array}{llll}3.96 & 182.4 & 196.7 & -103.7\end{array}\right]$

Reducing the theoretical response time of the observer by increasing the magnitude of the desired pole locations resulted in unrealistic values for the observer gains. Feedback to the controller is the glass temperature estimate from the observer. As shown in Figure 5-G, the estimation error does not converge in a reasonable amount of time. After simulating 24 hours of furnace operation, the estimation error is still nearly 20 degrees. 


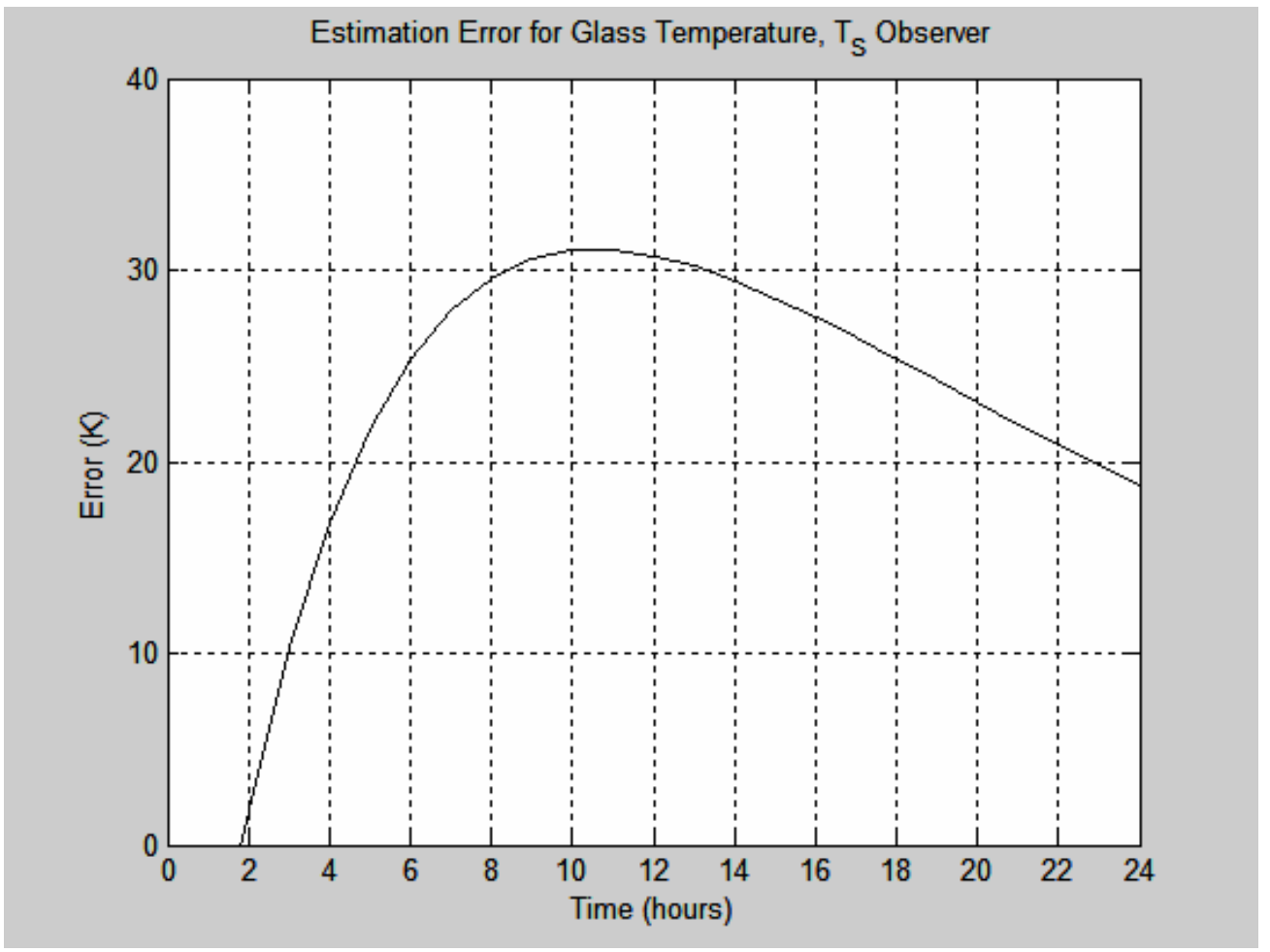

Figure 5-G: Estimation Error

Furthermore, as shown in Figure 5-H, the observer estimate of the glass temperature is lower than the actual gas temperature. Controlling the furnace based on this method would result in overheating the glass and excess fuel consumption. 


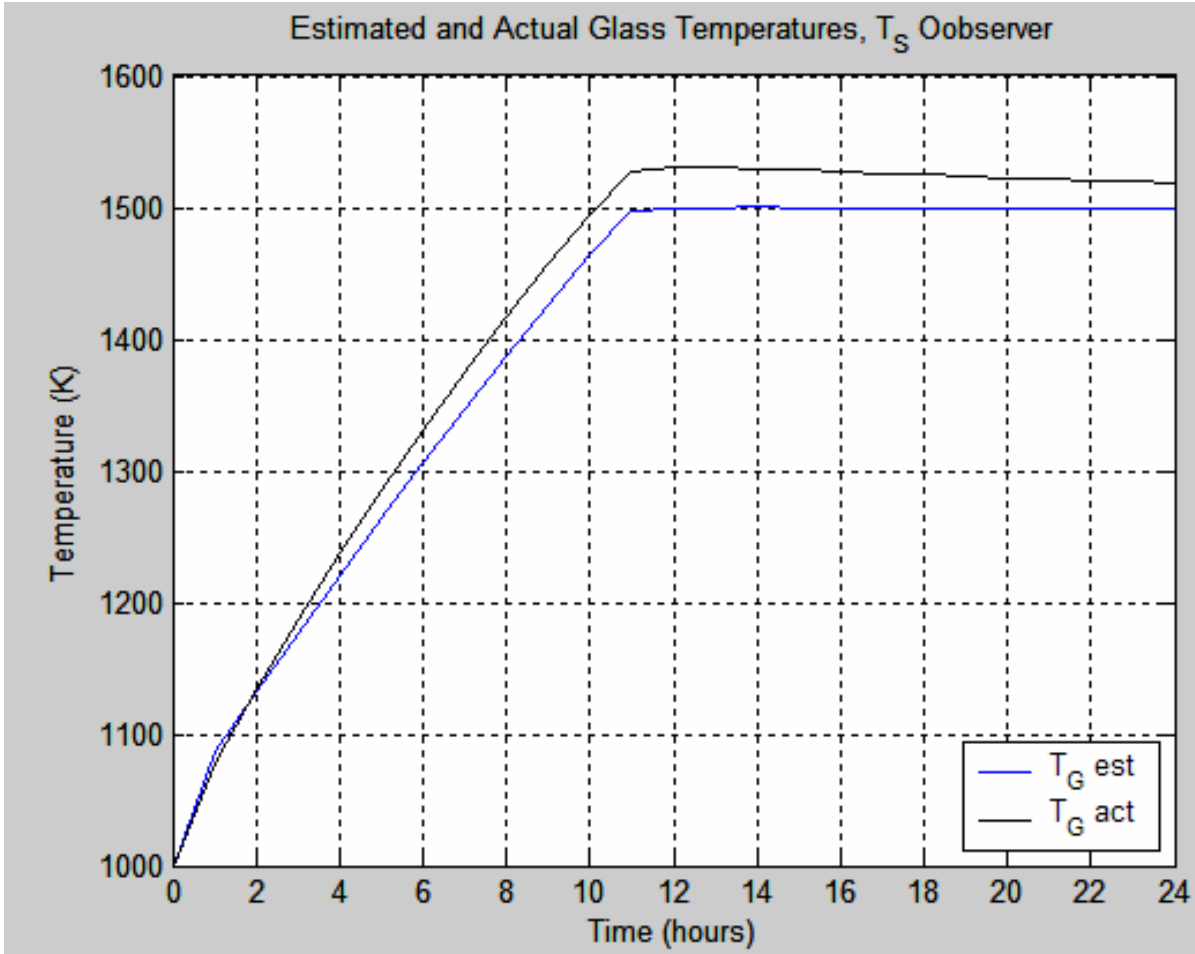

Figure 5-H: Estimated and Actual Glass Temperatures

The observer must also be robust to measurement noise and disturbance inputs. Measurement noise, common in nearly all instrumentation situations, is the result of small variations in voltage signals from sensors due to external influences like temperature changes or frequency interference. The measurement noise was modeled as zero mean Gaussian noise with an equivalent standard deviation of $0.5 \mathrm{~K}$.

A simulation including measurement noise over the entire simulation period and the glass removal disturbance input starting after 12 hours and 
continuing through the end of the simulation was run to show the combined effect of measurement noise and disturbance input on the $\mathrm{T}_{\mathrm{S}}$ observer. Figure 5-I, a plot of the estimation error, shows that the combined effect of measurement noise and a disturbance input further reduces the effectiveness of the observer based on combustion gas temperature. The observer is unable to satisfactorily track the system dynamics.

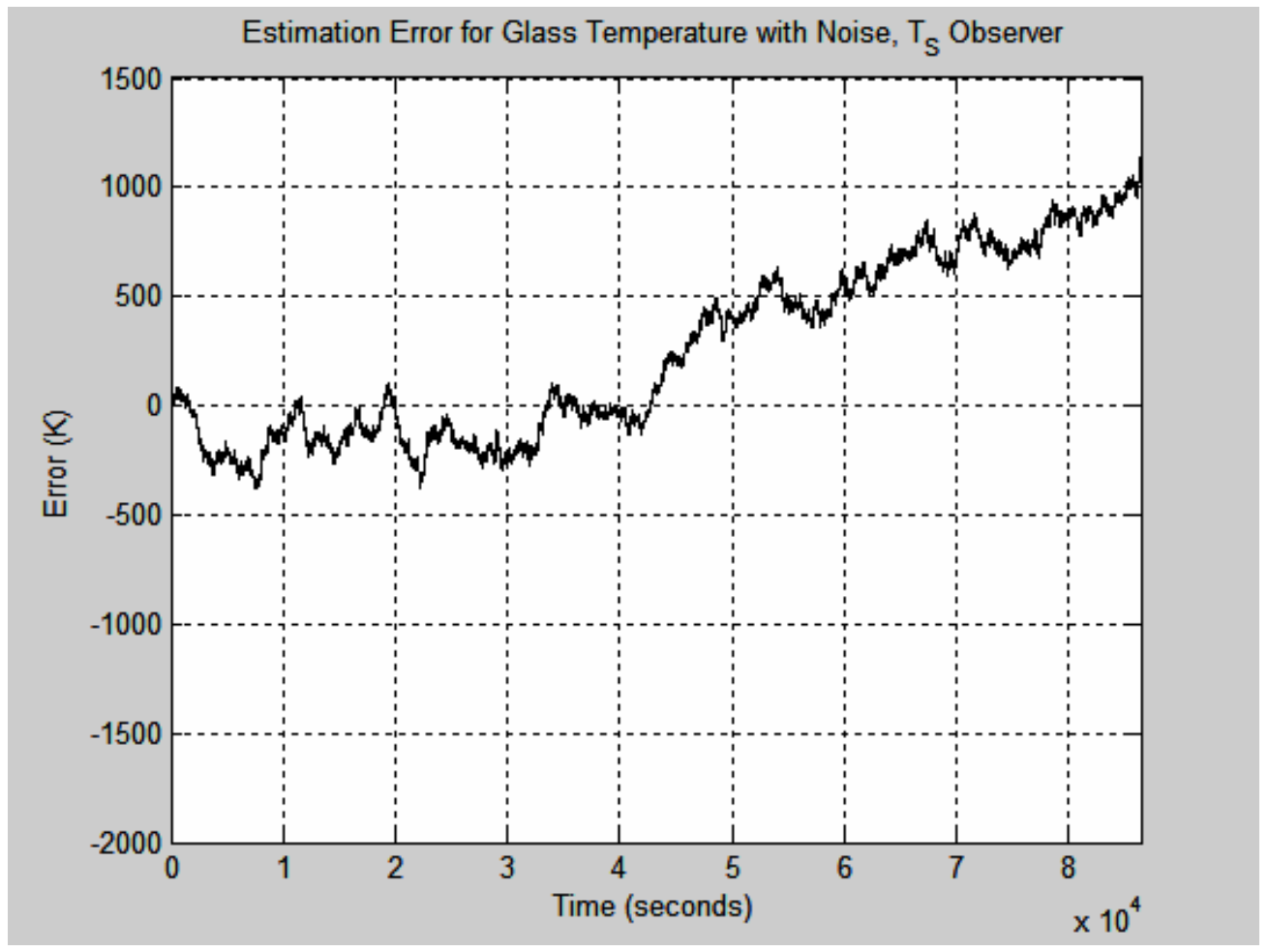

Figure 5-I: Estimation Error with Noise 
Because an observer based solely on combustion gas temperature measurements cannot provide accurate estimates of glass temperature within a reasonable time, another method must be investigated.

\section{Observer Based on Easily Measured States}

The remaining states in the dynamic model are glass temperature, refractory temperature in contact with the glass and refractory temperature above the surface of the glass. It has already been determined that measuring the glass temperature directly would not be a feasible option for a small glass company; but, measurement of the refractory temperatures would not be difficult or cost prohibitive. Refractory temperatures could be measured by simple thermocouples placed a known distance into the refractory bricks and insulated from ambient conditions. The bulk temperatures used in this thesis could be approximated by a bank of thermocouples placed in various places within the

furnace structure. Thermocouples capable of measuring refractory temperatures cost around $\$ 25$ (Type K) and do not require cooling air during operation like infra-red sensors.

An observer was designed based on available measurements of combustion gas, bottom refractory, and wall refractory temperatures using the 
same method as for the combustion gas observer with the following adjustments:

- Because of the additional state measurements the magnitude of the desired pole locations could be increased to [10 0.10 .05 $0.05]$

- The $\underline{C}$ matrix used for the observer was $\left[\begin{array}{llll}1 & 0 & 0 & 0 \\ 0 & 0 & 0 & 0 \\ 0 & 0 & 1 & 0 \\ 0 & 0 & 0 & 1\end{array}\right]$

The gains for this observer were then $\left[\begin{array}{cccc}-5.99 & 0 & 0 & 3.9124 \\ 0.0023 & 0 & 0.001 & 0 \\ 0 & 0 & 0.0497 & 0 \\ 0.001 & 0 & 0 & 9.99\end{array}\right]$

Figure 5-J shows the complete Simulink model of the observer with three state measurements. 


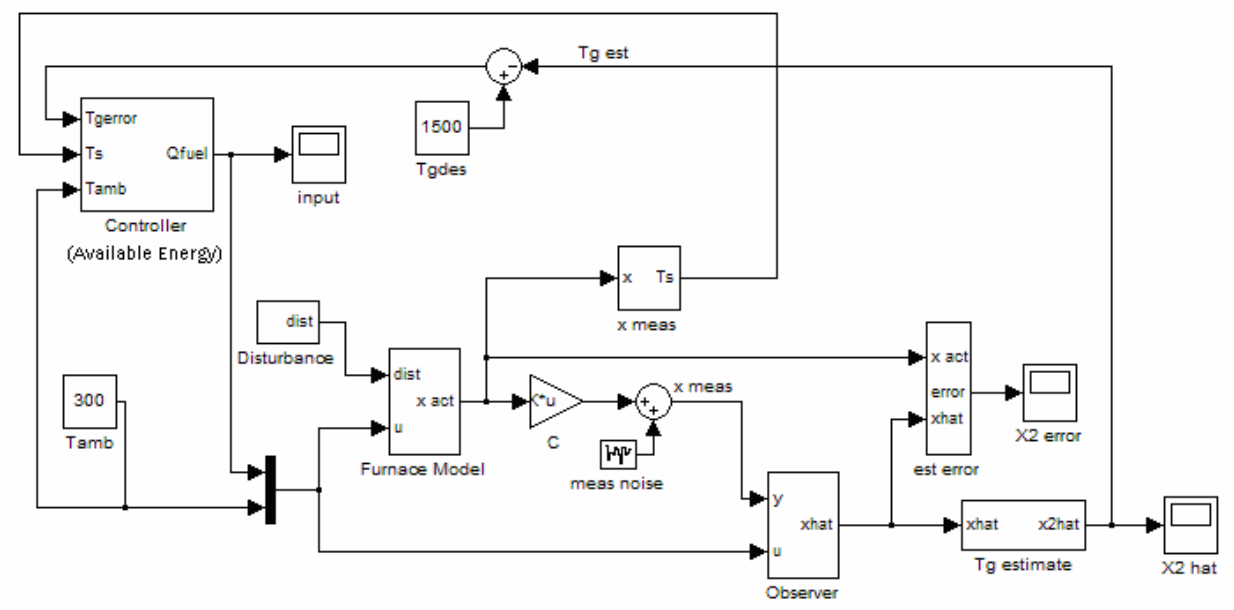

Figure 5-J: Simulink Model of Three State Observer

As shown in Figure 5-K, the estimated states track the calculated states exactly for the system without noise 


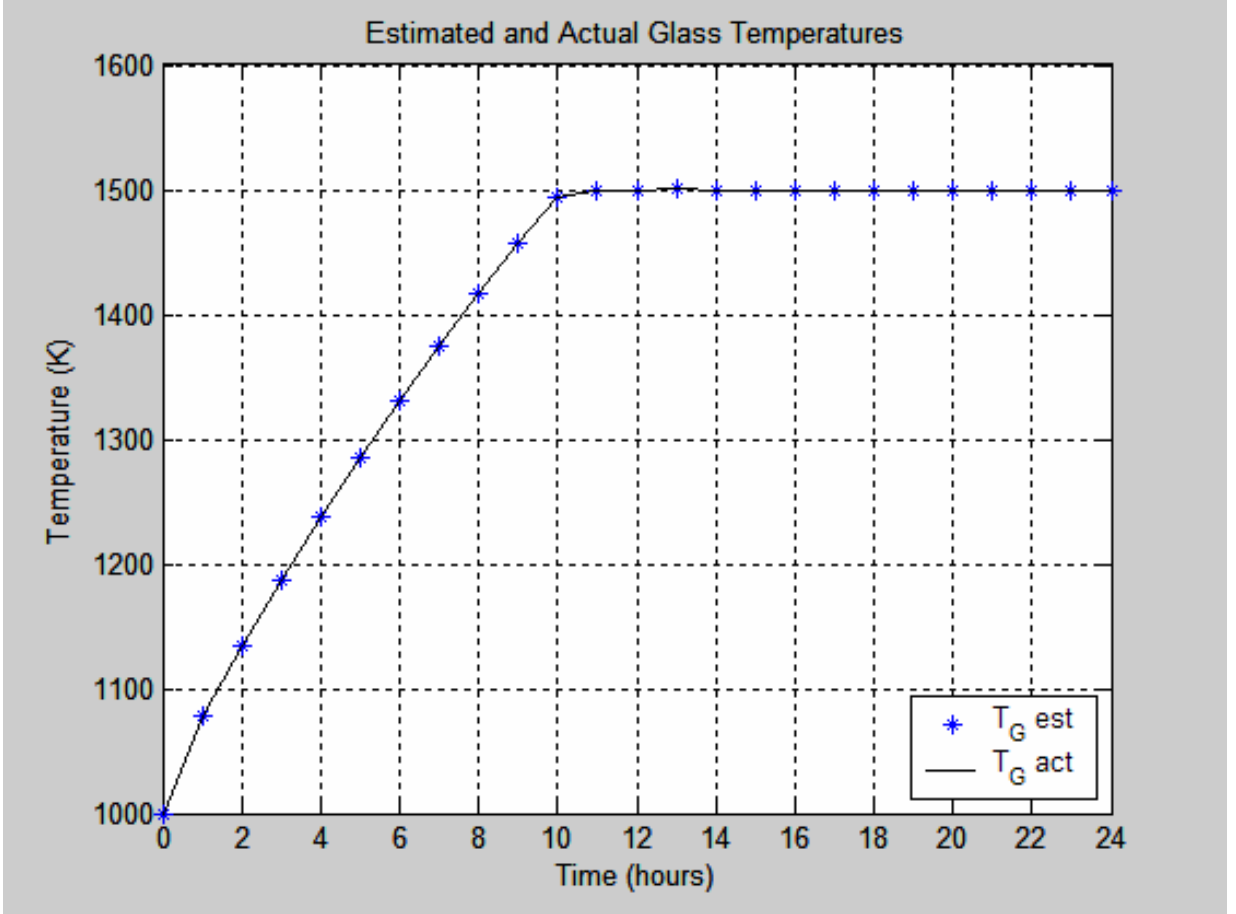

Figure 5-K: Estimated and Actual Glass Temperatures Three State Feedback

The estimation error is only apparent during the first few minutes of the simulation. The estimation error is shown in Figure 5-L. 


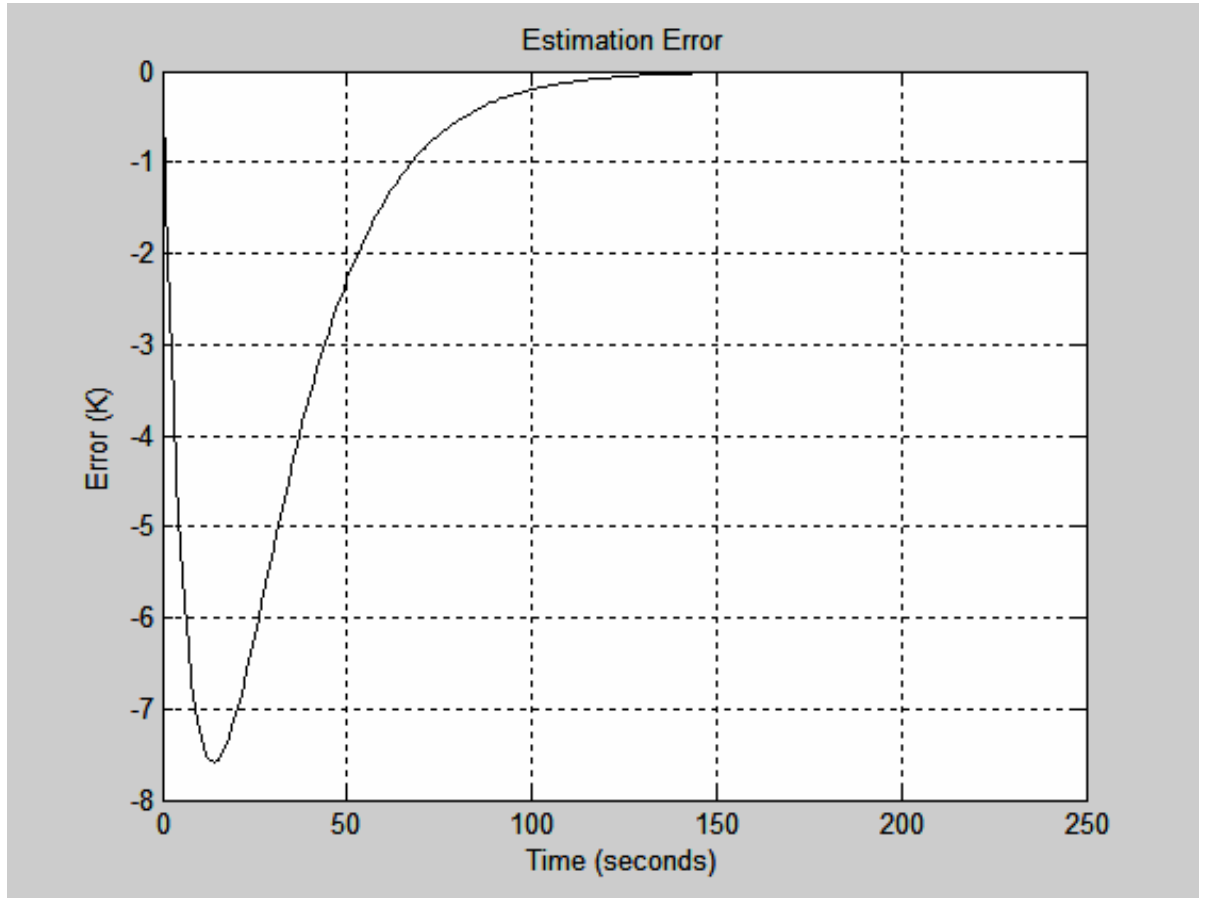

\section{Figure 5-L: Estimation Error for Three State Feedback}

This observer is also robust to disturbance inputs and measurement noise. To show that the observer is robust to disturbance input, the glass removal simulation was repeated. The temperatures were allowed to come to and remain at steady state for a period of 2 hours. The glass removal disturbance was applied over 3 hours. After 5 hours, the disturbance was removed and the system was allowed to return to steady state. Figure 5-M shows the temperature response of all four states when the glass temperature estimate from the observer is used for fuel control. A copy of Figure 5-E follows for comparison. 


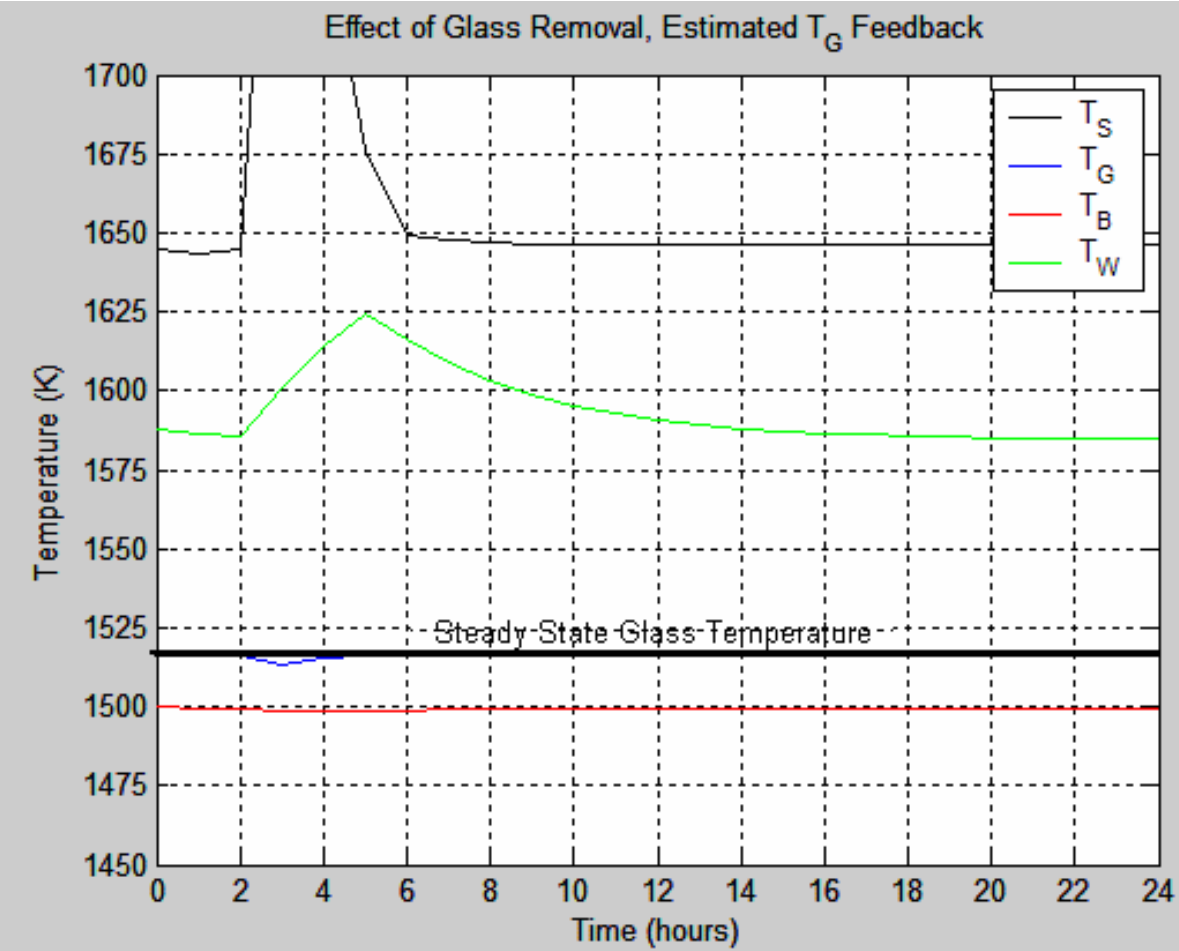

Figure 5-M: Effect of Glass Removal on $T_{G}-$ Three State Observer

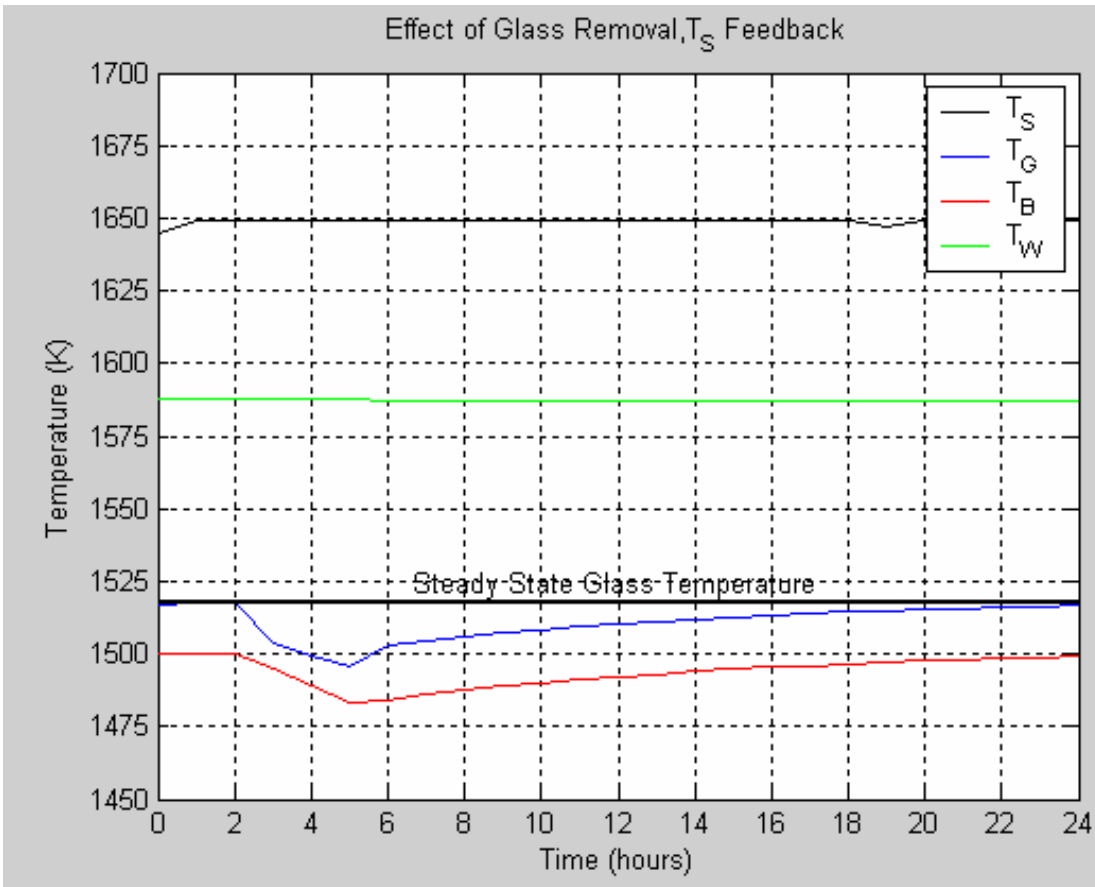

\section{Comparison Copy of Figure 5-E}


A detailed view of the glass temperature response over the period of glass removal is shown in Figure 5-N. The plot shows that the disturbance decreases the glass temperature by about 4.5 degrees, but because the observer is able to track this change, signal is sent to the controller to increase the fuel flow rate and increase the glass temperature.

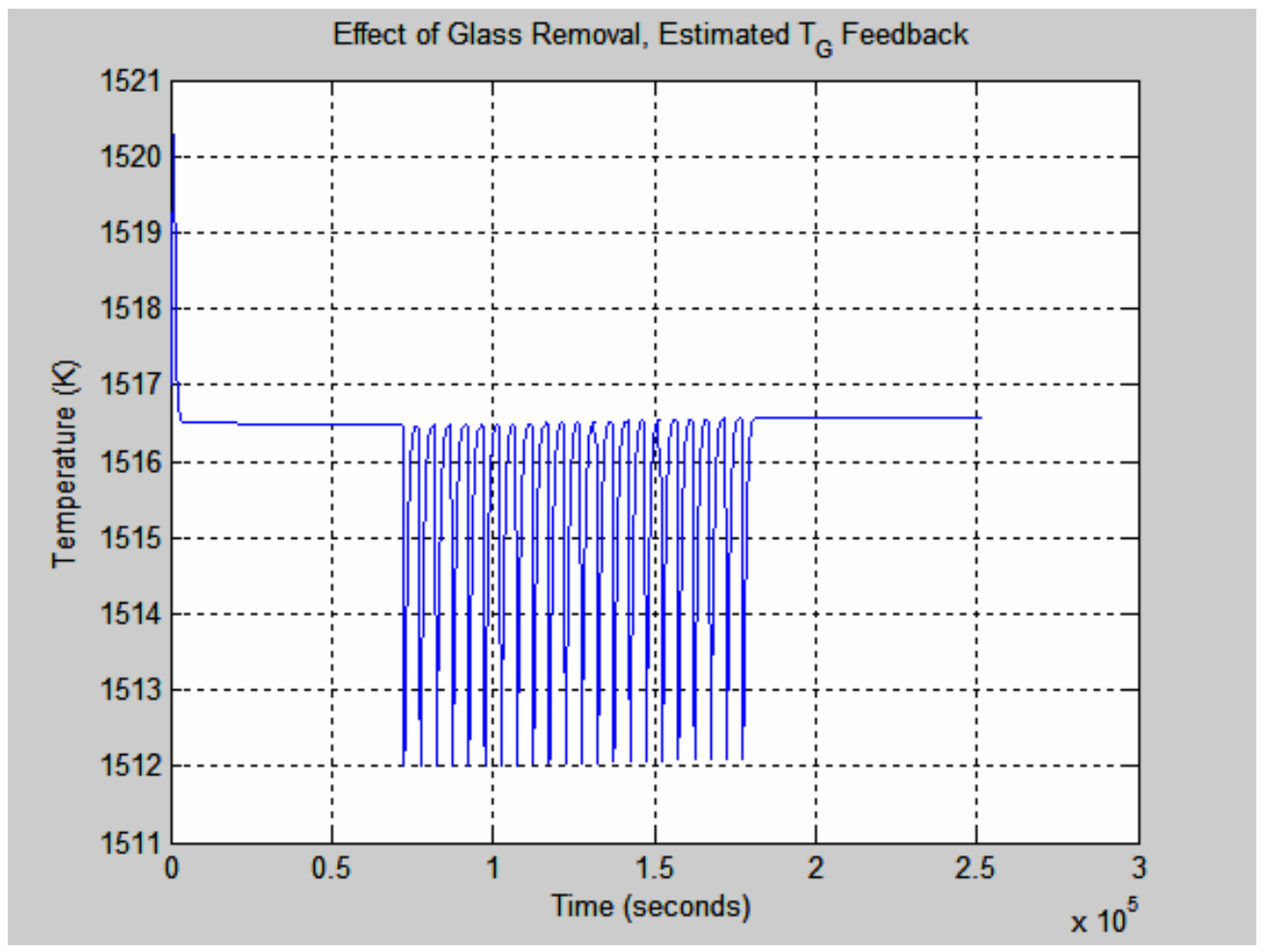

Figure 5-N: Detailed View of Glass Temperature with Disturbance

The necessary increase in fuel flow rate is shown in Figure 5-O for the detailed view and Figure 5-P for the entire simulation time. 


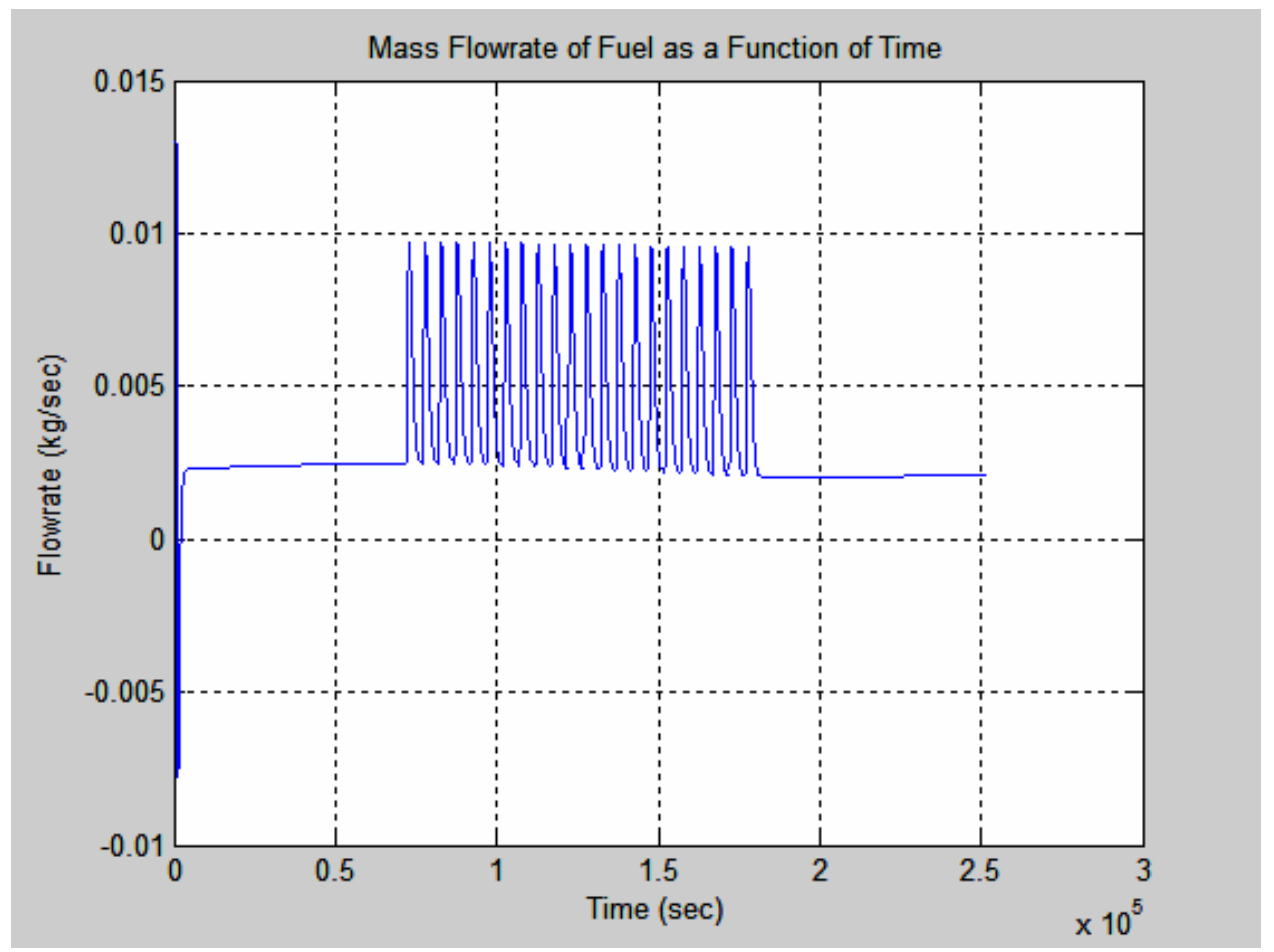

Figure 5-O: Detailed View of Fuel Flowrate with Disturbance

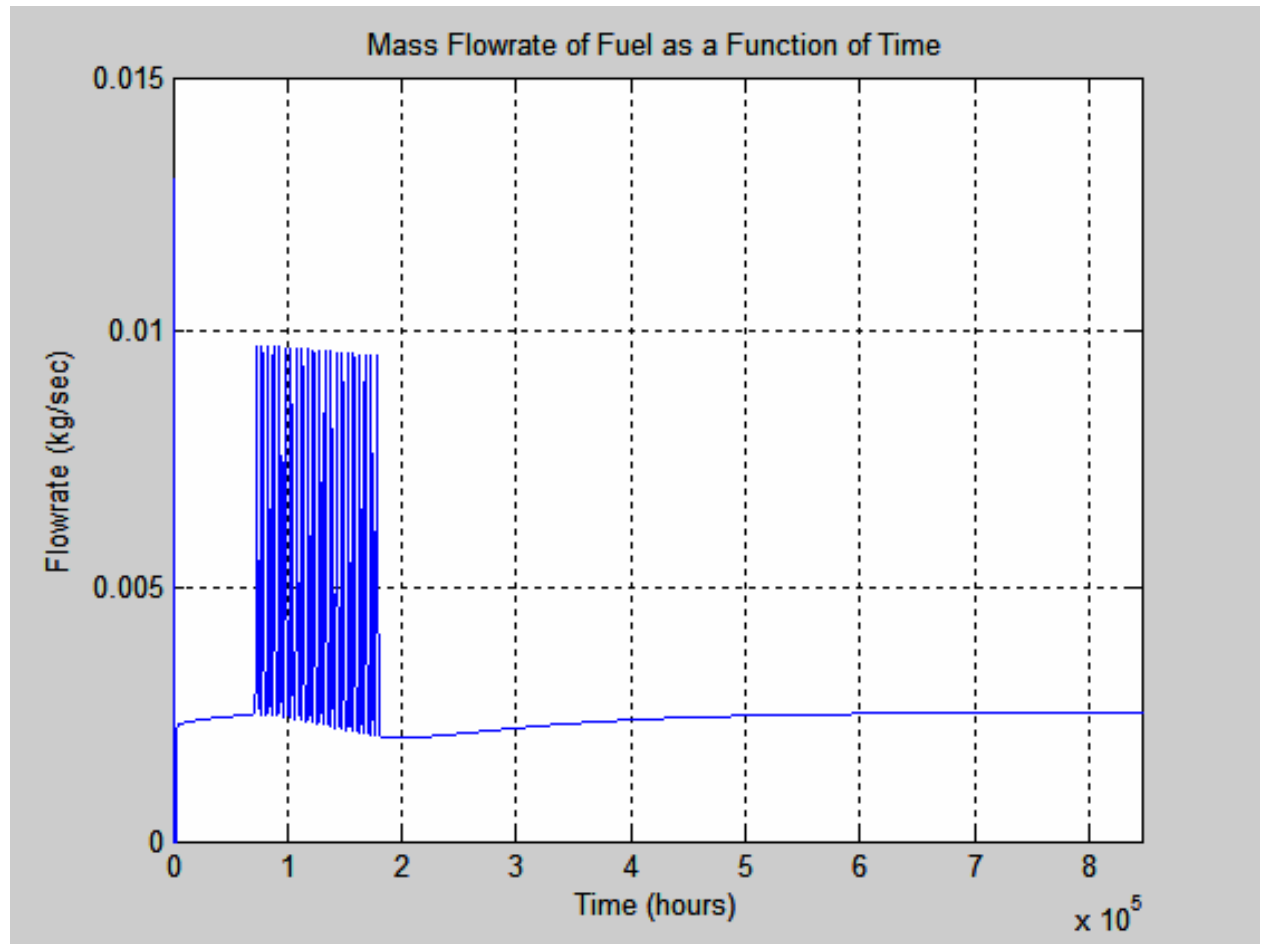

Figure 5-P: Flow rate of Fuel over Entire Simulation 
Figure 5-Q shows the estimated error under the combined effect of measurement noise and simulated glass removal. Measurement noise was added over the entire length of the simulation and the glass removal disturbance was added starting at 12 hours and continuing until the end of the simulation.

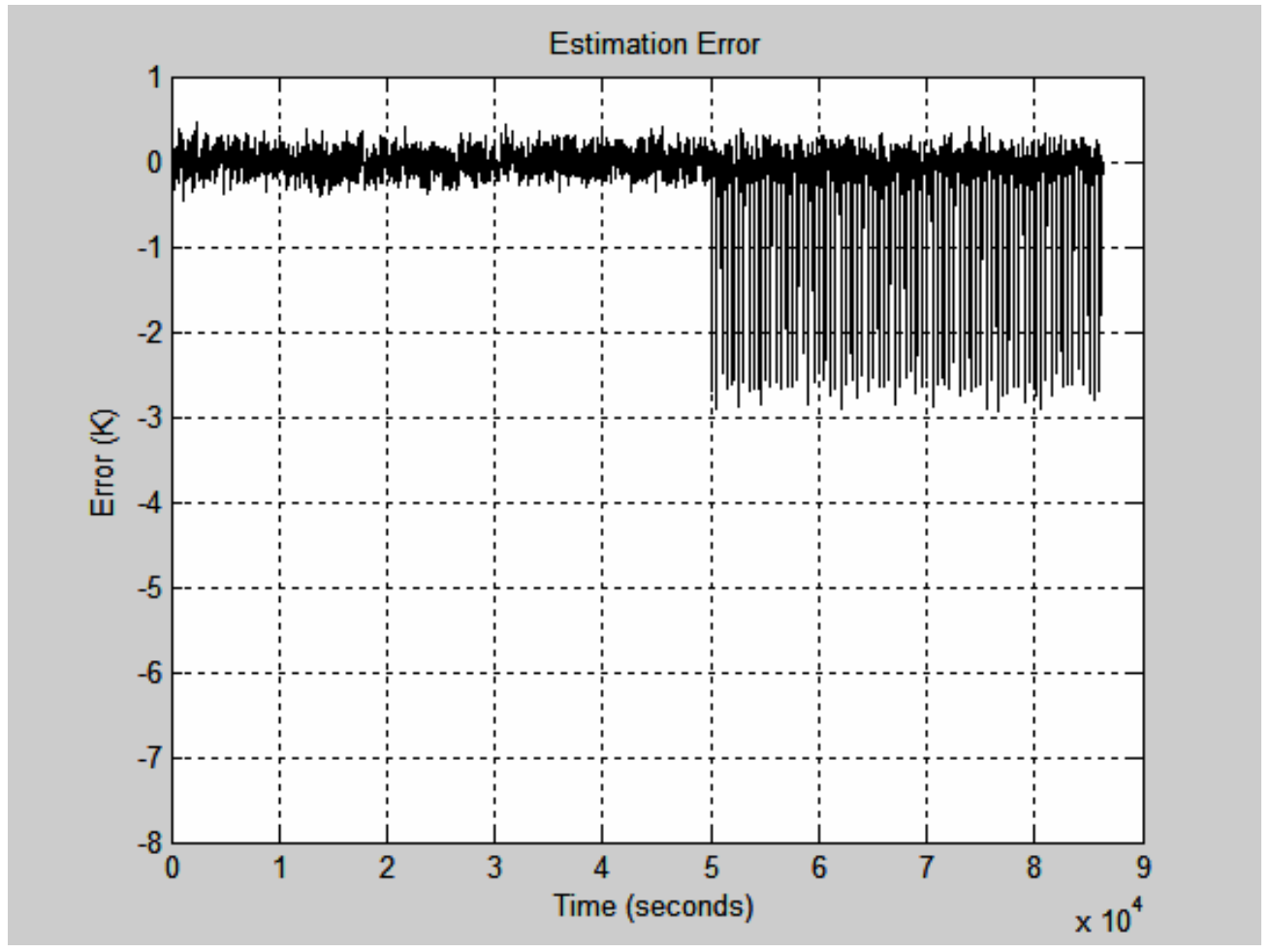

Figure 5-Q: Estimation Error Over 24 Hour Period with Noise 
Figure 5-R is a detailed view of the estimate error dynamics showing that the observer compensates for the addition of noise and disturbance inputs and that the magnitude of the error reaches a maximum of about 2.5 degrees.

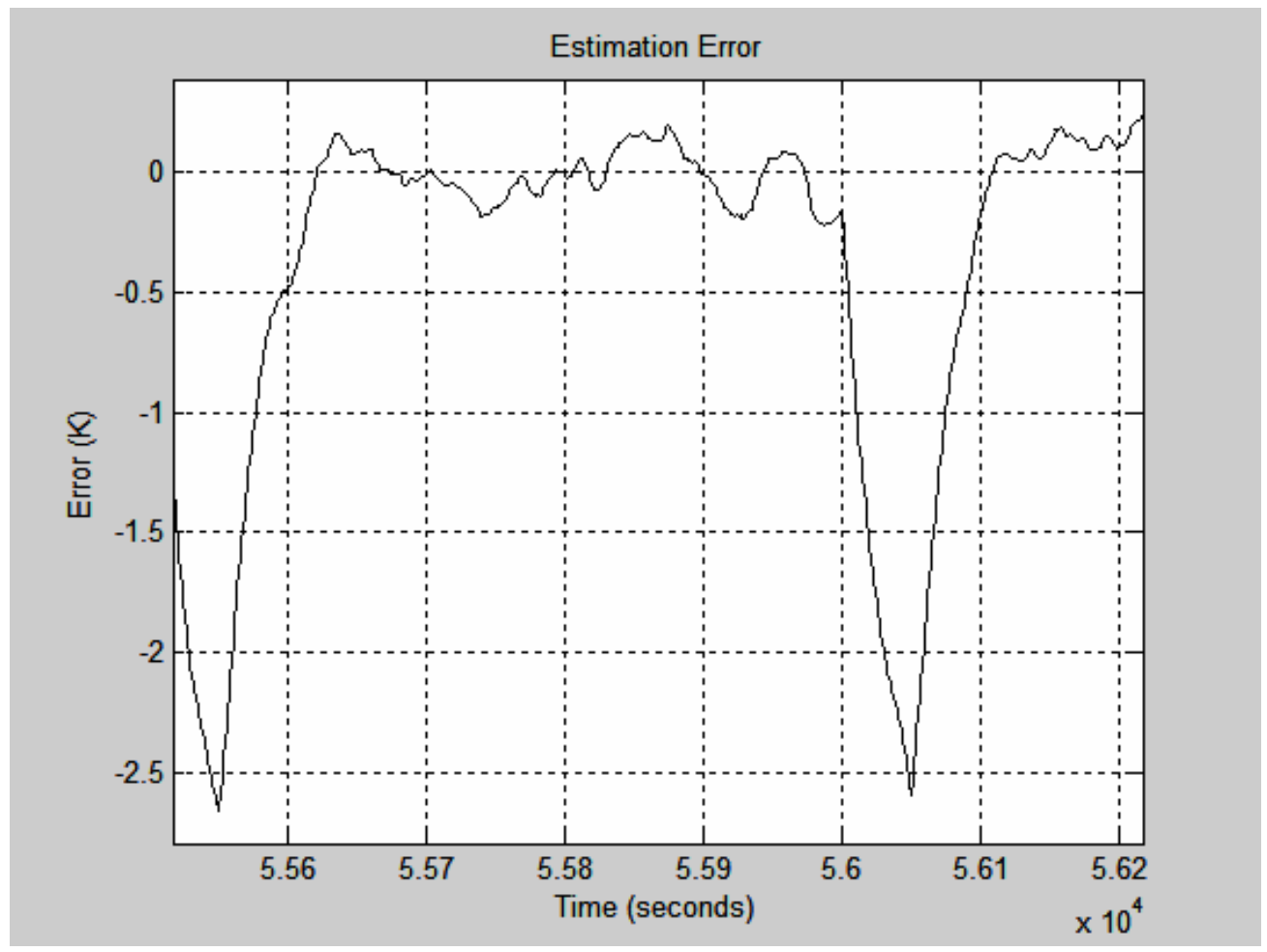

Figure 5-R: Detailed View of Estimation Error

The simulations performed show that an observer based on measurements of $\mathrm{T}_{\mathrm{S}}$ and refractory temperatures can accurately track system response and is robust to measurement noise and disturbance input. A system that implements this type of state estimation would be a cost-effective method of furnace control that makes available knowledge of glass temperature. 


\section{CONCLUSIONS AND RECOMMENDATIONS}

\subsection{Conclusions}

A lumped-parameter model of a small glass furnace has been designed for the purpose of developing an advanced, state-space controller capable of more sophisticated operation than can be realized by the single-loop controls currently prevalent in the industry. A number of advantages are offered by the state space approach, including the possibility of constructing an observer or state estimator for process parameters that are difficult to measure directly.

Currently, most small glass furnaces operate by measuring the temperature of the combustion gasses in the crown of the furnace, rather than the glass temperature directly. This is because molten glass is highly corrosive and destroys thermocouples relatively quickly when they are immersed in the melt. It is well-known and has been shown here by mathematical modeling that combustion gas temperature is an unreliable predictor of glass temperature. Reliance on $T_{S}$ measurements for process control will not produce acceptable results. This conclusion is borne out by the common industrial practice of gauging temperature by estimating the viscosity of the melt. 
Glass temperature can be measured directly using non-contact infrared temperature sensors. However, such equipment is fragile and relatively expensive. An alternative approach was developed here, in which two additional temperature measurements were combined with the customary crown temperature measurement to develop a state estimator for the glass temperature.

The additional measurements can be made using standard thermocouples placed in the furnace refractory in the crown and in the bottom of the tank. These additional measurements allow the development of an accurate estimator, robust to sensor noise and disturbance inputs, with rapid convergence characteristics. A controller based on the estimated glass temperature from the observer provides excellent temperature control and set point tracking. This system can be implemented at modest cost using off-the shelf hardware and a modest amount of programming. 


\subsection{Recommendations for Further Work}

Because the state estimator is specific to the furnace model, each installation would require the development of a mathematical model of the furnace and then tuning of the estimator. This would make the widespread application of this technology inconvenient and probably too expensive for many small glass manufacturers. The furnace model developed in this work could be recast to lend itself to online parameter identification. This would allow the controller to be connected to the system and allowed to self-calibrate to the particular furnace/burner/batch characteristics, greatly reducing the cost and complexity of installation. Such work would be an excellent "next step" for this technology.

In addition, the state space approach to control allows for much more sophisticated control modes than are available using current technology. Several possibilities come to mind. One lucrative example is the development of "optimal" control strategies for the melting, refining and working cycles. Time/temperature schedules could be optimized to provide minimum melt times, minimum energy melt cycles, or some compromise combination of these performance measures. Multiple programs could be set up on a digital computer-based control system to accommodate different product types, 
production schedules or fuel cost scenarios. Operator interfaces could be made much more informative and user-friendly than is possible with current single-loop controllers. Finally, a working hardware prototype should be developed and demonstrated on a glass furnace.

Furnace control is only one aspect of sound energy management in a glass plant. Numerous complementary strategies must be pursued to optimize furnace efficiency and maintain profitability. A sampling of these methods has been provided in Appendix B of this document. 


\section{BIBLIOGRAPHY}

1. Shelby, James E., Introduction to Glass Science and Technology, Royal Society of Chemistry, Cambridge, UK, 1997

2. Tooley, Fay V., The Handbook of Glass Manufacture, V. 2, 3ed, Ashlee Publishing Co. Inc., New York, NY, 1984 ISBN 0-91199321-5

3. Tooley, Fay V., The Handbook of Glass Manufacture, V. 1, 3ed, Ashlee Publishing Co. Inc., New York, NY, 1981 ISBN 0-91193320-7

4. Kokomo Glass Co., Inc., www.kog.com used with permission, Tom Giles, webmaster, Kokomo, IN, November 15, 2005.

5. Falorni Glass Furnaces, www.falorniglass.com, used with permission, Riccardo Scarselli, Empoli, Italy, November 15, 2005.

6. Verheijen, Oscar S., "Thermal and Chemical Behavior of Glass Forming Batches"-Eindhoven : Technische Universiteit Eindhoven, 2003 ISBN 90-386-2555-3

7. US Department of Energy , "Identifying Waste Heat Reduction Opportunities", www.eere.energy.gov/industry/bestpractices/emsum05 identifying waste heat reduction.html, September 18, 2005.

8. Hemingway, Bruce S., Bohlen, Steven R., Hankens, W.B., Westrum, Edgar F. Jr.,and Kuskov, Oleg L. "Heat Capacity and 
Thermodynamic Properties for Coesite and Jadite, Reexamination of the Quartz-Coesite Equilibrium Boundry", American Mineralogist, V 83, 409-18. 1998

9. "Monofrax CS-3 Alumina-Zirconia Silica (AZS) Fused Cast Refractory" Manufacturer's Literatre available at http://monofrax.com/A3077CS3W.pdf, October, 25, 2005.

10. 2001 ASHRAE Handbook Fundamentals, American Society of Heating, Refrigerating and Air-Conditioning Engineers, Inc., Atlanta, GA., 2001. ISBN 1-883413-87-7

11. McGraw, D. A., "Heat Transfer in the Glass-Mould Interface," Glastechnische Berichte (Glass Sci. Technol.), 46, 89-91 (1973).

12. Omega Model Number DP 1541, Two Color I/R System, Monitor and Sensors, http://www.omega.com/ppt/pptsc.asp?ref=DP1541\&Nav=temj12

13. Franklin, Gene F., Powell, J, David, Emami-Naeini, Abbas, Feedback Control of Dynamic Systems 4ed.Prentice Hall, Upper Saddle River, NJ, 2002 ISBN: 0-13-032393-4

14. US Energy Administration, "Official Energy Statistics from the U.S. Government", http://www.eia.doe.gov/ May 2, 2005

15. Beerkens, Ruud, G.C., "Energy Efficiency Benchmarking of Glass Furnaces", 62 ${ }^{\text {nd }}$ Conference on Glass Problems, October 16-17, University of Illinois at Urbana-Champaign, 2001. TNO Publications, http://www.tpd.tno.nl/smartsite497.html 
16. Ross, C. Philip and Tincher, Gabe L., PI., Rasmussen, Margaret, ed., "Glass Melting Technology. A Technological and Economic Assessment", Glass Manufacturing Industry Council with US DOE Industrial Technologies Program., October 2004.

17. "Preheated Combustion Air, Energy Tips Process Heat Tip Sheet \#1", U.S. Department of Energy, DOE/GO-102002-1551, May 2002, http://www.oit.doe.gov/ bestpractices/\%20process heat/

18. "An Electrostatic Batch Preheating System", 61st Conference on Glass Problems, Columbus, Ohio, (2000), http//www.stromstadengineering. com/electrobatch.html, March 18,2005

19. "Check Burner Air to Fuel Ratios, Process Heat Tip Sheet \#2", U.S. Department of Energy, DOE/GO-102002-1552, May 2002, http://www.oit.doe.gov/bestpractices/process heat/

20. "Monitoring Air/Fuel Mixtures in Glass and Glass Fiber Manufacturing", Themox® Application Note, Ametek Process Instruments, http://www.ametek.com, March 16, 2005

21. "High Temperature Acoustic Wave Gas Sensors For Automotive Exhaust and Industrial Stack Monitoring”, Factsheet, Sandia National Laboratories, http://www.sandia.gov/media/factsheets/99 rc high.html, September 12, 2004 


\section{Appendix A}

Heat Capacity Calulation for Monofrax Refractory

Cp formula $=a+b T+c T^{\wedge} 2+d / T$

\begin{tabular}{|l|l|r|r|r|r|r|}
\hline component & \multicolumn{1}{l|}{ MW } & \multicolumn{1}{l|}{ percent } & \multicolumn{1}{l|}{ a } & b & \multicolumn{1}{l|}{ c } & \multicolumn{1}{l|}{ d } \\
\hline ZrO2 & 123.22 & 0.34 & 60.88 & 22.32 & -1.6 & -3.37 \\
\hline Al2O3 & 101.96 & 0.49 & 154.96 & -16.168 & 7.12 & -20.817 \\
\hline SiO2 & 60.09 & 0.17 & 77.09 & 3.384 & -0.16 & -10.558 \\
\hline
\end{tabular}

\begin{tabular}{|c|c|c|c|c|c|c|c|}
\hline Temperature & & $\begin{array}{l}\text { Cp } \\
\text { molal }\end{array}$ & & & Cp mass & & $\begin{array}{l}\text { Cp } \\
\text { comp }\end{array}$ \\
\hline K & $\mathbf{Z}$ & $\mathbf{A}$ & $\mathbf{S}$ & $\mathrm{ZrO2}$ & Al2O3 & $\mathrm{SiO} 2$ & \\
\hline 1000 & 81.6 & 145.912 & 80.31399 & 0.66223 & 1.431071 & 1.336562 & 1.153598 \\
\hline 1050 & 82.552 & 145.8334 & 80.46679 & 0.669956 & 1.4303 & 1.339105 & 1.15628 \\
\hline 1100 & 83.496 & 145.7904 & 80.61879 & 0.677617 & 1.429878 & 1.341634 & 1.159108 \\
\hline 1150 & 84.432 & 145.783 & 80.76999 & 0.685213 & 1.429806 & 1.34415 & 1.162083 \\
\hline 1200 & 85.36 & 145.8112 & 80.92039 & 0.692745 & 1.430082 & 1.346653 & 1.165205 \\
\hline 1250 & 86.28 & 145.875 & 81.06999 & 0.700211 & 1.430708 & 1.349143 & 1.168473 \\
\hline 1300 & 87.192 & 145.9744 & 81.21879 & 0.707612 & 1.431683 & 1.351619 & 1.171888 \\
\hline 1350 & 88.096 & 146.1094 & 81.36679 & 0.714949 & 1.433007 & 1.354082 & 1.17545 \\
\hline 1400 & 88.992 & 146.28 & 81.51399 & 0.72222 & 1.43468 & 1.356532 & 1.179159 \\
\hline 1450 & 89.88 & 146.4862 & 81.66039 & 0.729427 & 1.436702 & 1.358968 & 1.183014 \\
\hline 1500 & 90.76 & 146.728 & 81.80599 & 0.736569 & 1.439074 & 1.361391 & 1.187016 \\
\hline 1550 & 91.632 & 147.0054 & 81.95079 & 0.743645 & 1.441795 & 1.363801 & 1.191165 \\
\hline 1600 & 92.496 & 147.3184 & 82.09479 & 0.750657 & 1.444865 & 1.366197 & 1.195461 \\
\hline 1650 & 93.352 & 147.667 & 82.23799 & 0.757604 & 1.448284 & 1.36858 & 1.199903 \\
\hline 1700 & 94.2 & 148.0512 & 82.38039 & 0.764486 & 1.452052 & 1.37095 & 1.204492 \\
\hline 1750 & 95.04 & 148.471 & 82.52199 & 0.771303 & 1.456169 & 1.373307 & 1.209228 \\
\hline 1800 & 95.872 & 148.9264 & 82.66279 & 0.778055 & 1.460635 & 1.37565 & 1.214111 \\
\hline & & & & & & ave & 1.18092 \\
\hline
\end{tabular}




\section{APPENDIX B}

\section{Energy Conservation Opportunities}

A high demand for more efficient melting processes has been created by the drastically increasing cost of fossil fuels. The primary fuel used for glass melting, natural gas, has seen a price increase of over $35 \%$ in the past 7 years and is predicted to increase another $20 \%$ by the year $2015 .{ }^{14}$

\begin{tabular}{|r|r|}
\hline \multicolumn{2}{|c|}{ United States } \\
Natural Gas \\
Industrial Price \\
\$/MCF \\
\hline 1997 & 3.59 \\
\hline 1998 & 3.14 \\
\hline 1999 & 3.12 \\
\hline 2000 & 4.45 \\
\hline 2001 & 5.24 \\
\hline 2002 & 4.02 \\
\hline 2003 & 5.81 \\
\hline 2004 & 6.41 \\
\hline
\end{tabular}

Table A-1 The cost of natural gas over the past 7 years. $^{14}$

The glass industry must take advantage of currently available and developing energy conservation opportunities, (ECOs), to remain viable. 
There are many opportunities for energy savings during the glass making process. Waste gas heat recovery will decrease the energy needed to melt the glass. Increased use of cullet- scrap or waste glass that can be recycled and re-melted, can decrease energy demand because the chemical reactions that take place during the melting of batch materials have already taken place. Electronic monitoring and control of the combustion and melting processes will optimize the energy that must be used. A combination of reduced energy consumption and improved process efficiency will have a positive impact on production costs.

\section{Waste Gas Heat Recovery}

Since the process of glassmaking occurs at very high temperatures, waste gas heat recovery is an ideal opportunity for energy savings. The pie chart in Figure A- A was created from a Sankey diagram of energy flows in the most efficient of 123 furnaces studied by R. Beerkens for a report

presented to the International Congress of Glass in $2001 .{ }^{15}$ The furnace modeled was a cross fired regenerative container furnace operating on $50 \%$ cullet. The energy recovered from regeneration in the original diagram was 
included in stack losses to represent a conservative example of process energy consumption in a typical furnace without regeneration or preheating.

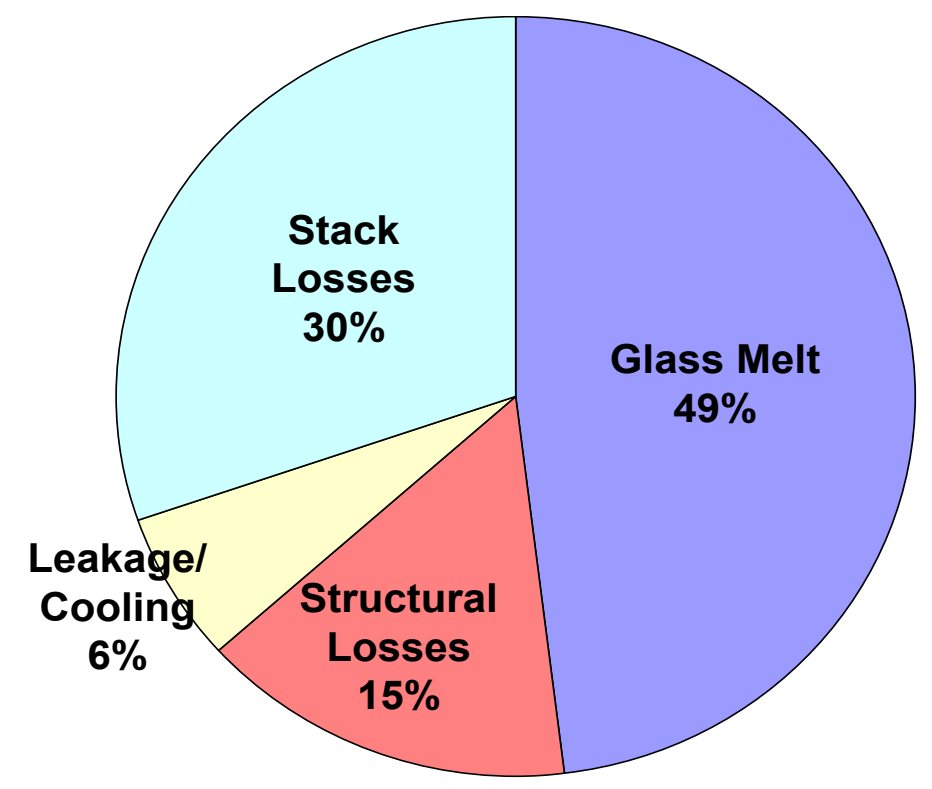

Figure A- A: Pie chart of process energy consumption in a glass melter

The temperatures of gasses leaving a typical tank furnace without heat recovery exceed $2400^{\circ} \mathrm{F} .{ }^{16}$ Energy from the high temperature exhaust can be used to pre-heat the combustion air, batch materials, or both. There are several heat recovery systems available to absorb energy present in exhaust gasses. 


\section{Combustion air preheating}

Most large furnaces incorporate regenerative cycles. A regenerative furnace has both a set of burners and a checker located on opposing walls of the melter. As one set of burners is firing, exhaust gasses flow through the checker on the opposite side and heat the bricks. Regenerative furnaces can preheat combustion air to more than $2000^{\circ} \mathrm{F}{ }^{16}$ The higher combustion air temperatures increase the thermal efficiency of the melter. Drawbacks to regenerative systems include increased capital costs due to installation and maintenance of the checkers and large space requirements. Regenertative systems are not often applied to small glass furnaces.

Smaller furnaces are typically recuperative systems. In a recuperative furnace, exhaust gasses flow through a metal heat exchanger which indirectly heats a separate flow of combustion air. Recuperative furnaces are less expensive but also less efficient than regenerative furnaces. Combustion air temperatures from a recuperator can only reach about $800^{\circ} \mathrm{F} .{ }^{16}$ Although recuperative furnaces are not as energy efficient as regenerative furnaces, substantial amounts of heat are still recovered. Lower combustion air temperatures also contribute to lower $\mathrm{NO}_{\mathrm{X}}$ emissions. The decrease in exhaust 
gas heat loss as a percentage of input due to preheating combustion air is shown in Figure A- B.

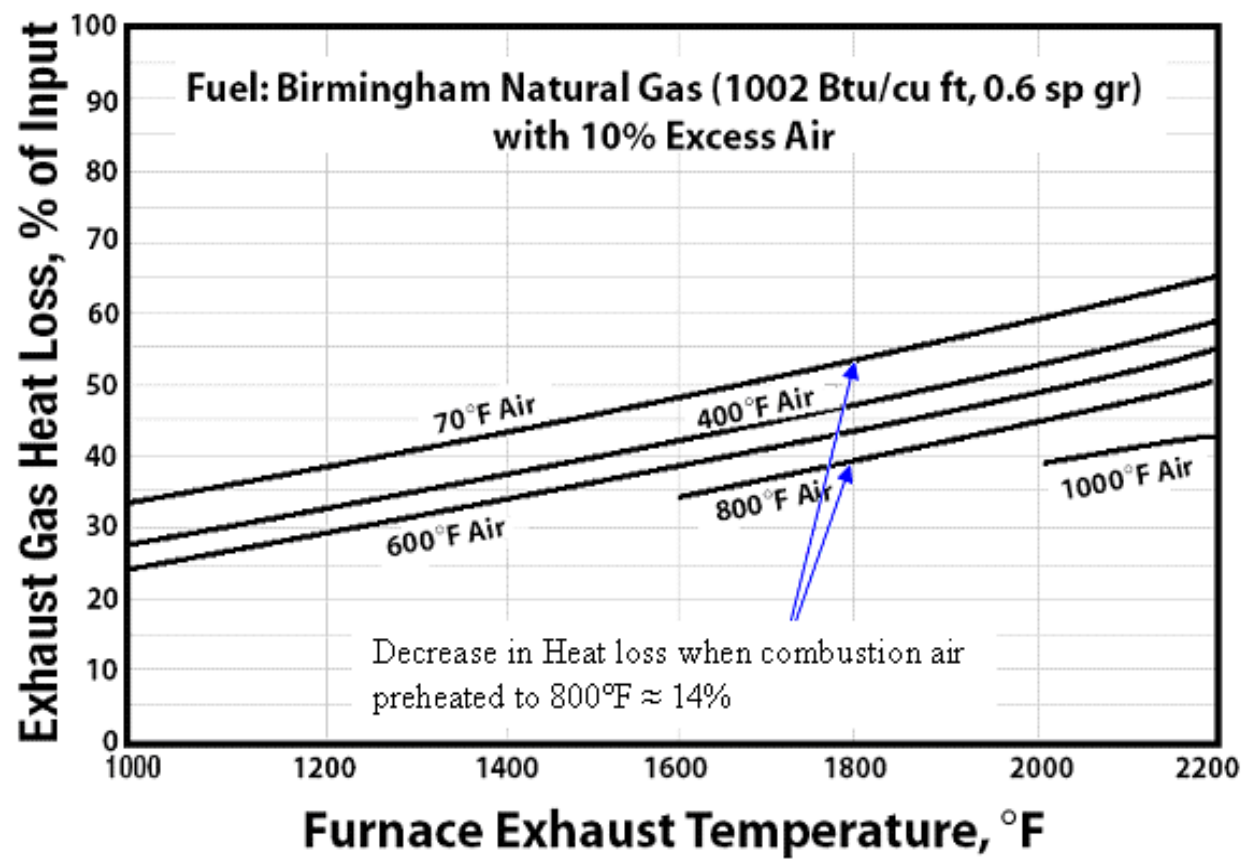

Figure A- B: Exhaust gas heat loss as a function of combustion air temperature $^{17}$

Energy efficiency in recuperative furnaces can be further improved by batch/cullet preheating, gas preheating, or installing waste heat boilers.

\section{Batch Material Preheating}

Methods of preheating batch materials include counterflow-crossflow heat exchangers, raining bed preheaters, electrified cullet beds, electrostatic 
batch preheating, and the Nienburger Glas Batch Preheater. For each method, there are restrictions on which materials can be preheated. Some methods can only be used to heat cullet, some can only heat batch and some can be used to heat combinations of batch and cullet. The restrictions are related to particle size and dust production. Limitations of preheat temperatures for all methods occur at around $1050-1100^{\circ} \mathrm{F}$ due to softening of the glass which causes difficulty in handling and feeding.

Counterflow-crossflow preheaters are plate type heat exchangers in which batch and exhaust gasses are separated by metal plates. Exhaust gas flows upward from the furnace to the exhaust stack though several channels. Cullet/batch material is added at the top and moves down through alternate channels in the preheater to the batch mixing or feeding mechanism. Benefits of this type of preheater include small pressure losses in exhaust stream and no sulfur contamination of the batch due to products of combustion. Disadvantages include lower efficiency than direct contact methods and no opportunity for particulate in exhaust to be returned to the furnace. Batch temperature can be preheated to over $600^{\circ} \mathrm{F}$ with this method. ${ }^{16}$

Raining bed preheaters can be used with batch or cullet or a combination of batch and cullet. Batch materials enter at the top and fall 
through the counterflowing exhaust stream, bouncing off of $45^{\circ}$ plates spaced throughout the preheater. A cyclone is located at the top of the preheater to gather and return the particulate to the preheater discharge. Advantages include high heat transfer rates and low capital cost. Disadvantages include construction materials (high temperature, acid resistant metals) and reliability. Batch materials can be preheated to around $1100^{\circ} \mathrm{F}$ with this method. ${ }^{16}$

Electrified cullet bed preheaters, also called Electrified Granulate Bed (EGB), are systems that use a bed of cullet about 12-18 inches thick to filter the exhaust gasses. Cullet is continuously added to the top of the preheater and removed from the bottom. Gasses leaving the furnace are ionized, which creates an electric charge on dust particles in the exhaust stream. The ionized particles and exhaust pass through the cullet bed. A high voltage electrode within the cullet bed polarizes the cullet. The charged dust particles attach to the polarized cullet. The cullet is then fed to the furnace. Benefits to this system include cleaner exhaust gasses and efficient heat transfer to the cullet. Disadvantages to this system include the electricity requirement of the electrode and a restriction on cullet size due to the associated pressure drop through the cullet bed. Cullet can be preheated to around $750^{\circ} \mathrm{F}$ with this method. ${ }^{16}$ 
Electrostatic batch preheating or "E-batch" is similar to a cross flow heat exchanger. Hot exhaust gasses flow through open bottom channels in a zig-zag pattern from the bottom to the top of cylindrical bin. Batch is loaded at the top and fed to the furnace from the bottom of container. A schematic of the E-batch system is shown in Figure A- C.

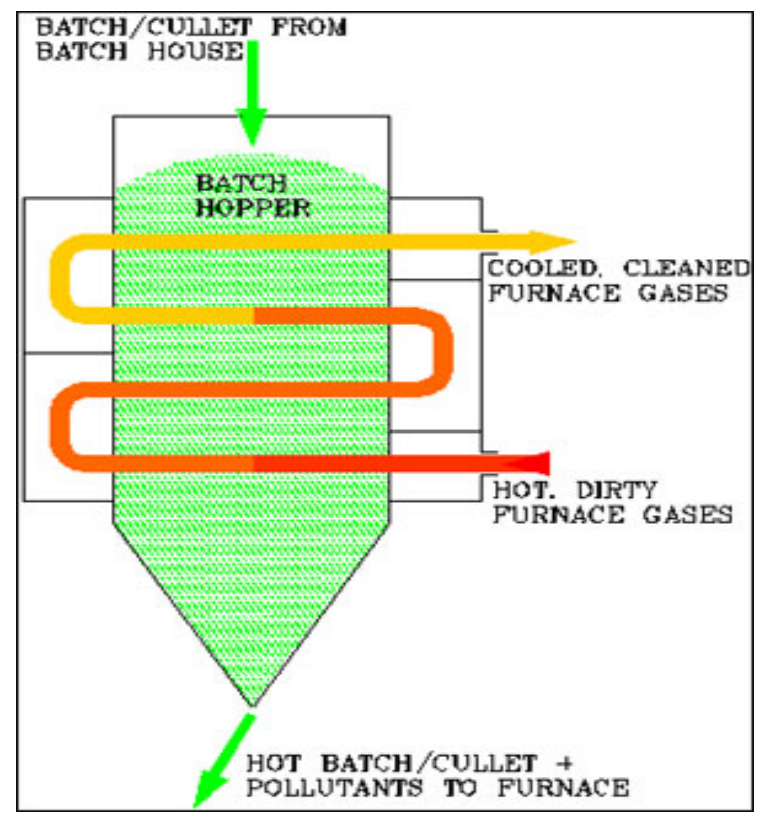

Figure A- C: Schematic of E-Batch System ${ }^{18}$

The open bottom tubes allow for direct contact of the exhaust gasses and the batch as the material moves through the preheater. Chemical reactions between some batch materials and exhaust acids (primarily soda ash and SOx) produce sulfate solids that will remain in the batch. These reactions help scrub the exhaust gasses but are not effective in removing the particulate produced 
by the process. An electrostatic device precipitates the particulate from the exhaust stream back onto the batch surface at the furnace feeding end of the preheater. Advantages to this method are adaptability to existing batch handling and furnace charging equipment and high temperature preheating of cullet (over $900^{\circ} \mathrm{F}$ ). Disadvantages include the use of electricity and installation expense. $^{16}$

The most proven of the 5 methods discussed is the Nienburger Glas Batch Preheater. This technology has been implemented in five German glass facilities. After 12 years of use, the preheater has demonstrated a 20 percent reduction in furnace energy use and proportional (due to lower fuel consumption) reductions in $\mathrm{NOx}^{16}$

In this method, batch materials and exhaust gasses are in direct contact within a hopper providing enhanced heat transfer and reducing SOx emissions. Flue gasses are directed through the preheater in counterflow to the raw materials. As with the E-Batch system, an electrostatic precipitator is placed downstream to collect particulate in the exhaust stream. Unlike other systems, the Nienburger preheater is designed to act as the batch storage bin instead of an intermediate stage between storage and feeding. Advantages to this system 
include proven effectiveness and efficient heat transfer. Disadvantages include the need for electricity and retrofit expenses. ${ }^{16}$

Energy savings for cullet/batch preheating depend on the temperature to which the material is raised. Capital investment and payback periods will vary depending on the type of system selected and current furnace design.

\section{Combustion Efficiency Management}

Management and control of air/fuel ratios in natural gas furnaces has a direct impact on energy requirements. More refined combustion control will increase efficiency and decrease pollutants $\left(\mathrm{CO}, \mathrm{NO}_{2}\right)$. As, shown in Figure A- D, combustion efficiency quickly decreases as percent excess air increases. Manufacturers should monitor A/F ratios and be able to control the air and fuel flows to maintain the desired ratio at each burner. 


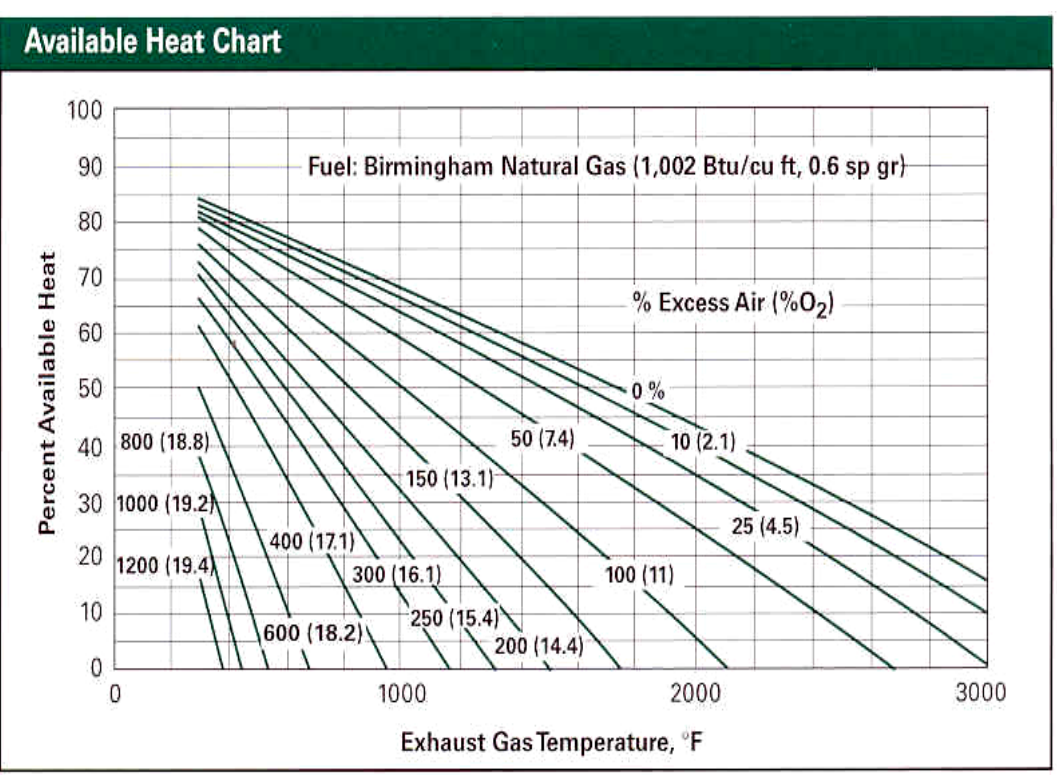

\section{Figure A- D: Combustion Efficiency ${ }^{19}$}

\section{Combustion Analysis}

Ideally, combustion products should be analyzed as well mass flow rates. Feedback from the combustion analysis should be used to maintain desired $\mathrm{A} / \mathrm{F}$ ratios, compensate for disturbances in air and fuel flows (fuel heating value, atmospheric conditions), and alert operators of potential problems (clogged burners, air infiltration, excess pollutants).

For a given fuel composition, $\mathrm{A} / \mathrm{F}$ ratios can be determined by a simple mathematical ratio of mass flow rates. Since the mass flows of both the fuel and the air are not linearly proportional to damper/valve openings, both the 
flow rates should be measured by mass flow and not by percent damper/valve opening. Mass flow rates can be determined by either pitot tubes or orifice plates located in supply lines.

A premix combustion analyzer can also be used to determine $\mathrm{A} / \mathrm{F}$ ratios. If the air and fuel is mixed before the burner, then a sample can be diverted into a small controlled chamber where it is completely combusted. The products of combustion are measured with a zirconium oxide cell. Since this technique is performed before individual burner combustion instead of in the exhaust stack, results will not be affected by variances in other burners or leaks in the furnace or stack. ${ }^{20}$

Combustion efficiency and air fuel ratios can also be measured in the exhaust. High temperature acoustic wave gas sensors utilize a piezoelectric material as part of an electronic oscillator circuit. Changes in the properties of the gas stream create changes in the frequency of the oscillation. These sensors can be used to monitor $\mathrm{H}_{2}, \mathrm{CO}, \mathrm{CO}_{2}, \mathrm{NO}_{\mathrm{x}}, \mathrm{SO}_{2}$, water vapor and some hydrocarbons. ${ }^{21}$

Zirconium Oxide sensors are overwhelmingly the most common type of combustion analyzer. The zirconium oxide cell responds electrically to the 
presence of oxygen in the exhaust stack. Reverse calculations can be performed to obtain $\mathrm{A} / \mathrm{F}$ ratios.

\section{Reduce Waste Glass/Scrap from Forming Processes}

Glass producers should constantly be investigating methods of reducing waste and scrap from forming processes. For example:

- excess glass gathered in a blowpipe becomes scrap

- many molding/pressing operations create excessive moile, or include "pedestals" that may contain as much glass as the product

- Poorly controlled processes produce defective product that must be scrapped

- A significant percentage of product is often broken in material handling operations or in the annealing lehr 
Throughout the manufacturing industry, profit margins are decreasing as fuel costs continue to rise. These shrinking profit margins are especially noticeable in the glass industry where fuel can account for over $70 \%$ of a plant's total production cost. Smaller glass manufacturing facilities, where profit margins are already lower, can be devastated by increasing fuel costs. Implementing and maintaining energy conservation techniques are crucial to insuring the viability of these companies in the future.

Of the Energy Conservation Opportunities discussed in this paper, combustion efficiency management, combustion air preheating, and batch/cullet preheating should be made priorities. Payback periods for these ECOs are relatively short and these measures can significantly reduce fuel consumption. Decreasing waste glass/ scrap from forming processes has an immediate payback and methods for reducing waste should be constantly investigated.

Along with implementing the suggested ECOs, other recommendations include: 
- Glass companies should communicate with others throughout the industry and create a collective knowledge base for energy conservation opportunities.

- Do not limit research to industry specific programs. Technology created for another industry could be applied to glass production. Burner design, temperature sensors and control systems are examples of such technologies.

- Within each company, there should be a system for monitoring and recording energy consumption to all processes. This data should be used to monitor production costs and to verify energy conservation methods that have been implemented. Variances in energy consumption can pinpoint manufacturing issues such as broken sensors, disconnected wires, furnace cracks or leaks, and heat exchanger failures.

- Verify data and operating procedures. Be certain that operators are following proper guidelines and that production data is recorded 
accurately. These items should be monitored by personnel not directly affected by department quotas.

- Create a task force or committee within the company consisting of upper management and representatives from each department. This team should meet on a regular basis to discuss and suggest energy conservation techniques

- Invest in a plant wide energy assessment. An assessment can either be done in house or with the help of the Department of Energy. Information for the DOE assessment programs can be found at http://www.oit.doe.gov/bestpractices/assessments.shtml

Overall, it is important to remember that investigating energy conservation methods should be a continuous process. New technologies are constantly emerging. Projects previously determined to be too expensive to implement may become feasible as energy costs increase. 